\title{
Systems biology-based analysis implicates a novel role for vitamin $D$ metabolism in the pathogenesis of age-related macular degeneration
}

\author{
Margaux A. Morrison, ${ }^{1,2}$ Alexandra C. Silveira,' Nancy Huynh, ' Gyungah Jun, ${ }^{3}$ Silvia E. Smith, ${ }^{2}$ Fani Zacharaki, ${ }^{4}$ \\ Hajime Sato,' Stephanie Loomis,' Michael T. Andreoli,' Scott M. Adams,' Monte J. Radeke, ${ }^{5}$ Austin S. Jelcick, ${ }^{6}$ \\ Yang Yuan, ${ }^{6}$ Aristoteles N. Tsiloulis, ${ }^{4}$ Dimitrios Z. Chatzoulis, ${ }^{4}$ Giuliana Silvestri, ${ }^{7}$ Maria G. Kotoula, ${ }^{4}$ Evangelia E. Tsironi, \\ Bruce W. Hollis, ${ }^{8}$ Rui Chen, ${ }^{9}$ Neena B. Haider, ${ }^{6}$ Joan W. Miller, ${ }^{10}$ Lindsay A. Farrer, ${ }^{1 /}$ Gregory S. Hageman, ${ }^{2}$ \\ Ivana K. Kim, ${ }^{10}$ Debra A. Schaumberg ${ }^{12}$ and Margaret M. DeAngelis $1,2^{*}$ \\ 'Ocular Molecular Genetics Institute, Harvard Medical School, Massachusetts Eye and Ear, Boston, MA, USA \\ ${ }^{2}$ Department of Ophthalmology and Visual Sciences, University of Utah, Salt Lake City, UT, USA \\ ${ }^{3}$ Departments of Medicine (Section of Biomedical Genetics), Ophthalmology and Biostatistics, Boston University Schools of \\ Medicine and Public Health, Boston, MA, USA \\ ${ }^{4}$ Department of Ophthalmology, University of Thessaly School of Medicine, Larissa, Greece \\ ${ }^{5}$ Center for the Study of Macular Degeneration, Neuroscience Research Institute, University of California, Santa Barbara, CA, USA \\ ${ }^{6}$ Department of Genetics, Cell Biology and Anatomy, University of Nebraska Medical Center, Omaha, NE, USA \\ ${ }^{7}$ Centre for Vision and Vascular Science, Queen's University, Belfast, UK \\ ${ }^{8}$ Pediatric Nutritional Sciences, Medical University of South Carolina, Charleston, SC, USA \\ ${ }^{9}$ Department of Molecular and Human Genetics, Baylor College of Medicine, Houston, TX, USA \\ ${ }^{10}$ Retina Service, Harvard Medical School, Massachusetts Eye and Ear, Boston, MA, USA \\ "'Departments of Medicine (Section of Biomedical Genetics), Ophthalmology and Biostatistics, Neurology, Epidemiology, \\ Boston University Schools of Medicine and Public Health, Boston, MA, USA \\ ${ }^{12}$ Division of Preventive Medicine, Brigham and Women's Hospital and the Department of Ophthalmology, Harvard Medical School, \\ Boston, MA, USA \\ *Correspondence to: Tel: +1 801213 4052; Fax: +1 801581 5335; E-mail: margaret.deangelis@utah.edu
}

Date received (in revised form): 22 June 2011

\begin{abstract}
Vitamin D has been shown to have anti-angiogenic properties and to play a protective role in several types of cancer, including breast, prostate and cutaneous melanoma. Similarly, vitamin D levels have been shown to be protective for risk of a number of conditions, including cardiovascular disease and chronic kidney disease, as well as numerous autoimmune disorders such as multiple sclerosis, inflammatory bowel diseases and type I diabetes mellitus. A study performed by Parekh et al. was the first to suggest a role for vitamin $D$ in age-related macular degeneration (AMD) and showed a correlation between reduced serum vitamin $D$ levels and risk for early AMD. Based on this study and the protective role of vitamin $D$ in diseases with similar pathophysiology to AMD, we examined the role of vitamin $D$ in a family-based cohort of $48 \mathrm{I}$ sibling pairs. Using extremely phenotypically discordant sibling pairs, initially we evaluated the association of neovascular AMD and vitamin D/sunlight-related epidemiological factors. After controlling for established AMD risk factors, including polymorphisms of the genes encoding complement factor $\mathrm{H}(\mathrm{CFH})$ and age-related maculopathy susceptibility $2 / \mathrm{HtrA}$ serine peptidase (ARMS2/HTRAI), and smoking history, we found that ultraviolet irradiance was protective for the development of neovascular AMD $(p=0.00 \mathrm{I})$. Although evaluation of serum vitamin $\mathrm{D}$ levels (25-hydroxyvitamin $\mathrm{D}[25(\mathrm{OH}) \mathrm{D}])$ was higher in unaffected individuals than in their affected siblings, this finding did not reach statistical significance.
\end{abstract}


Based on the relationship between ultraviolet irradiance and vitamin D production, we employed a candidate gene approach for evaluating common variation in key vitamin $D$ pathway genes (the genes encoding the vitamin $D$ receptor [VDR]; cytochrome P450, family 27, subfamily B, polypeptide I [CYP27BI]; cytochrome P450, family 24, subfamily A, polypeptide I [CYP24A I]; and CYP27AI) in this same family-based cohort. Initial findings were then validated and replicated in the extended family cohort, an unrelated case-control cohort from central Greece and a prospective nested case-control population from the Nurse's Health Study and Health Professionals Follow-Up Studies, which included patients with all subtypes of AMD for a total of 2,528 individuals. Single point variants in CYP24AI (the gene encoding the catabolising enzyme of the vitamin D pathway) were demonstrated to influence AMD risk after controlling for smoking history, sex and age in all populations, both separately and, more importantly, in a meta-analysis. This is the first report demonstrating a genetic association between vitamin $\mathrm{D}$ metabolism and AMD risk. These findings were also supplemented with expression data from human donor eyes and human retinal cell lines. These data not only extend previous biological studies in the AMD field, but further emphasise common antecedents between several disorders with an inflammatory/immunogenic component such as cardiovascular disease, cancer and AMD.

Keywords: vitamin D, age-related macular degeneration

\section{Introduction}

Several biological processes/cellular pathways involved in conditions such as cancer, cardiovascular disease and type 1 diabetes have also been implicated in the pathophysiology of the neovascular form of age-related macular degeneration (AMD). AMD, a disease characterised by the loss of ability to drive, recognise faces and read, is the leading cause of blindness in the US elderly population. Most prominent among these shared disease-associated processes is angiogenesis, the defining hallmark of neovascular AMD. ${ }^{1-3}$ Additionally, immune cell involvement, inflammation and oxidative stress have all been associated with these diseases. ${ }^{2,4-19}$

Vitamin D is a circulating steroid hormone which is thought to be protective in a variety of cancers, including breast, prostate and cutaneous melanoma. ${ }^{20-23}$ Although classically associated with bone mineralisation and the regulation of $\mathrm{Ca}^{2+}$ and phosphorus $\left(\mathrm{P}_{\mathrm{i}}\right),{ }^{24}$ vitamin $\mathrm{D}$ has been demonstrated to have anti-angiogenic and anti-inflammatory effects. ${ }^{25-28}$ In addition, it has been shown to play a role in cellular proliferation, differentiation and apoptosis, as well as protecting cell proteins and membranes from oxidative damage. ${ }^{20,29,30}$

Vitamin D synthesis and metabolism begins upon cutaneous ultraviolet (UV) B exposure, resulting in the conversion of 7-dehydrocholesterol to vitamin D. In addition to UVB, sources of vitamin $\mathrm{D}$ include diet and supplements. ${ }^{20}$ In the liver, cytochrome $\mathrm{P} 450$, family 27 , subfamily $\mathrm{B}$, polypeptide 1 (CYP27B1) catalyses the conversion of vitamin $\mathrm{D}$ to its pro-hormonal major circulating form, 25-hydroxyvitamin D $(25(\mathrm{OH}) \mathrm{D})$. CYP27A1 then converts $25(\mathrm{OH}) \mathrm{D}$ to the biologically active form of vitamin $\mathrm{D}\left[1,25(\mathrm{OH})_{2} \mathrm{D}_{3}\right] .{ }^{31}$ The biologically active form of vitamin $\mathrm{D}$ binds to the nuclear hormone receptor vitamin $\mathrm{D}$ receptor gene $(V D R)$. VDR heterodimerises with retinoid $\mathrm{X}$ receptor alpha to regulate transcription by binding vitamin $\mathrm{D}$ response elements in gene promoters and recruiting transcriptional co-factors. ${ }^{32}$ The active form of vitamin $\mathrm{D}$ is eventually catabolised after processing in the kidney or liver by cytochrome P450, family 24, subfamily A, polypeptide 1 (CYP24A1). ${ }^{33}$ Parekh et al. demonstrated an inverse relationship between serum vitamin $D$ levels and early AMD but could not extrapolate the findings to advanced AMD, potentially owing to the small number of patients studied in this category $(n=10) .{ }^{34}$ Based on this association and the involvement of vitamin $\mathrm{D}$ in processes underlying several diseases with an inflammatory or immune component, we hypothesised that vitamin D might play a role in AMD pathophysiology and, in particular, neovascular AMD. A special focus was placed on neovascular AMD, as it is the advanced 
form of AMD that accounts for the majority of cases of severe vision loss and it is necessarily preceded by an early form of the disease. To evaluate comprehensively the contribution of vitamin D and vitamin D pathways to neovascular AMD and, moreover, all subtypes of AMD, we conducted epidemiological, biological and genetic studies initially on a family-based cohort. This was followed by replication and validation of significant genetic findings in an unrelated case-control cohort from central Greece, as well as two prospective cohorts comprising AMD cases and controls from the Nurse's Health Study (NHS) and Health Professionals Follow-Up Studies (HPFS).

An epidemiological study was conducted to determine the association of dietary supplements, UV light and sun-related variables, including iris colour, self-reported sun exposure and skin cancer history, with neovascular AMD. Serum levels of vitamin $\mathrm{D}$ were also examined to assess further the contribution of vitamin D levels to advanced AMD risk. To assess if genetic variation within vitamin $\mathrm{D}$ metabolism genes might be associated with neovascular AMD, tagging single nucleotide polymorphisms (SNPs) within the vitamin D pathway genes CYP27B1, CYP27A1, CYP24A1 and VDR were genotyped to find significantly associated AMD risk variants and haplotypes within a discovery cohort comprising extremely discordant sibling pairs that is, where one sibling, the index patient, has the neovascular form of AMD and the other sibling has no signs of AMD and is older than 65 years of age. Moreover, CYP27B1, CYP27A1, CYP24A1 and $V D R$ were chosen because they are vitamin $\mathrm{D}$ pathway genes that are located in genomic regions previously implicated in AMD disease susceptibility. ${ }^{35,36}$ Based on findings of genetic association within this extremely discordant sibpair discovery cohort, we replicated and validated findings in our other cohorts as described below.

\section{Material and methods}

\section{Family-based patient population}

The protocol was reviewed and approved by the Institutional Review Boards at the Massachusetts
Eye and Ear Infirmary (MEEI), Boston, MA, USA, and conformed to the tenets of the Declaration of Helsinki. Eligible patients were enrolled in this study after giving informed consent and before completing a standardised questionnaire and donating $10-50 \mathrm{ml}$ of venous blood.

Details of the recruitment of the sibling pairs, comprising mainly individuals of European ancestry, are described in detail elsewhere. ${ }^{37,38}$ Briefly, the disease status of every participant was confirmed by at least two investigators by evaluation of fundus photographs or fluorescein angiograms, except when one of the investigators directly examined an unaffected sibling during a home visit ( $n=4$ cases).

All index patients were approximately 50 years of age or older and had the neovascular form of AMD in at least one eye, defined by subretinal haemorrhage, fibrosis or fluorescein angiographic presence of neovascularisation. Patients whose only exudative finding was a retinal pigment epithelium (RPE) detachment were excluded because this finding may not represent definite neovascular AMD. Patients with signs of pathological myopia, presumed ocular histoplasmosis syndrome, angioid streaks, choroidal rupture, any hereditary retinal diseases other than AMD, and previous laser treatment due to retinal conditions other than AMD were also excluded.

Patients with an early/intermediate form of dry AMD were classified according to the Age-Related Eye Disease Study (AREDS) ${ }^{39}$ as either category 2 (small $[<63 \mu \mathrm{m}]$ drusen with total area $\geq 125 \mu \mathrm{m}$, or at least one intermediate druse $[\geq 63$ and $<125 \mu \mathrm{m}$ ], or presence of pigment abnormalities); or AREDS category 3 (intermediate drusen comprising total area $\geq 360 \mu \mathrm{m}$ in the presence of soft drusen, or $\geq 656 \mu \mathrm{m}$ in the absence of soft drusen, or at least one large druse $[\geq 125 \mu \mathrm{m}]$, or noncentral geographical atrophy), as previously described for this cohort. ${ }^{40}$

The unaffected siblings had normal maculae and were aged at least 65 years or older at the time at which the index patient was first diagnosed with neovascular AMD. These criteria were based on published epidemiological studies that indicated that elderly individuals with such maculae rarely go 
on to develop neovascular AMD during a ten-year follow-up. ${ }^{41}$ Unaffected maculae fulfilled the following criteria: 0-5 small drusen (all less than $63 \mu \mathrm{m}$ in diameter), no pigment abnormalities, no geographical atrophy and no neovascularisation (as defined previously; AMD 'category 1 or less' on the AREDS scale ${ }^{39}$ ).

\section{Replication cohorts}

Replication of significant findings was performed on three unrelated case-control cohorts. The central Greece cohort (as previously described ${ }^{40}$ ) included patients without AMD (controls; $n=$ 198), with early and intermediate dry AMD (AREDS category 2 and $3 ; n=84$ ) and with neovascular AMD $(n=139)$ (Table S1). These patients were recruited from the medical retina outpatient clinic at the University Hospital of Larissa, Greece. The diagnosis of macular degeneration was confirmed by optical coherence tomography and fluorescein angiography. Colour fundus photography and indocyanine green angiography were performed in some cases.

A second replication cohort was a prospective, nested case-control sample of participants from two cohorts: the NHS and HPFS. Details of these studies and ascertainment of AMD cases have been previously described. ${ }^{40,42,43}$ This combined NHS/ HPFS AMD cohort contained 1,527 individuals, including 293 with the early or dry form of AMD (AREDS category 2 and 3) and associated vision loss to $20 / 30$ or worse, 164 with the neovascular form of the disease (AREDS category 4) and 1,070 age-matched controls who remained free of AMD during the follow-up period (Table S1).

\section{Epidemiological data}

Data were obtained by conducting telephone or in-person interviews to complete a standardised questionnaire. Data included iris colour as blue (light), green (medium) or brown (dark). The regular use of multivitamins or vitamin D supplements was ascertained if supplements were taken at least twice a week for at least six months prior to the index patient's diagnosis of AMD. Smoking data, as measured in pack years (as described previously ${ }^{37}$ ), was available for every participant. Briefly, a smoker was defined as smoking $\geq 10$ pack-years and a non-smoker as smoking less than 10 pack-years in their lifetime.

To quantify sunlight exposure, average UV radiation (UVR) exposure was calculated for the location at which each subject lived for the majority of his or her lifetime on 133 sibpairs, for a total of 276 individuals. Latitude, longitude and elevation for each city and state were determined using the website http://www.topozone.com. Using the calculated longitude (range, -123.0363.19), latitude (range, 25.99-46.49) and elevation (range, $0.001-1.598 \mathrm{~km}$ ) for each participant's city and state, UVR exposure was obtained using the tropospheric UV-visible (TUV) calculator found at the website http://cprm.acd.ucar.edu/Models/ TUV/Interactive_TUV/, using input option 1: latitude and longitude, and output 2: irradiance, weighted. The TUV calculator uses a model that corrects for the effects of cloud cover, based on data collected from November 1978 to June 2000, as described on the website. UVR index and UVA and UVB irradiances were reported in watts $/ \mathrm{m}^{2}$ for noon on the 15th of each month for the year 2006 in order to assess UV exposure throughout the year. Additionally, UV measures were taken on two specific dates: summer solstice and winter solstice, as these two days may have different UV exposures, being the longest and shortest days of the year, respectively. Yearly UV exposure was calculated as the average of all the recorded exposures.

To validate our findings of association between UV exposure and AMD, we obtained additional UV data on our family-based cohort from a separate source. The monthly average UV index was determined using the website for the US Environmental Protection Agency's SunWise Program (http:// www.epa.gov/sunwise1/doc/uvimonth.html). The website reports average monthly exposure in terms of UV index, based on data from the years 1994-2008. Yearly exposure was calculated by averaging monthly exposures obtained for the location at which each subject lived for the majority of their lifetime. 
Self-reported sun exposure was also obtained, to account for cumulative sun exposure. Self-reported sun exposure was recorded for both current and separately - 15 years ago, as one of four categories: (i) spends most of the day outside; (ii) spends most free time outside; (iii) occasionally spends a day in the sun; or (iv) almost never outside.

\section{Measurement of circulating vitamin D}

For the collection of sera, non-fasting blood was drawn from 50 sibling pairs (100 subjects) in the discovery cohort of extremely discordant sibling pairs. Blood was collected into BD Vacutainer SST tubes (BD, Franklin Lakes, NJ, USA) and samples were centrifuged at room temperature (approximately $20^{\circ} \mathrm{C}$ ) at $1500 \mathrm{~g}$ for 10 minutes. Serum was immediately drawn off and stored at $-80^{\circ} \mathrm{C}$ in $2.0 \mathrm{ml}$ cryogenic tubes (Corning Life Sciences, Lowell, MA, USA).

Levels of circulating $25(\mathrm{OH}) \mathrm{D}$ were measured in $\mathrm{ng} / \mathrm{ml}$, according to previously described methods. ${ }^{44}$ Patients were classified as deficient if serum 25(OH)D was less than $20 \mathrm{ng} / \mathrm{ml}$; as insufficient if levels were between 21 and $29 \mathrm{ng} / \mathrm{ml}$; and as sufficient if levels were between 30 and $150 \mathrm{ng} / \mathrm{ml}^{24}$ Serum 25(OH)D levels greater than $150 \mathrm{ng} / \mathrm{ml}$ were classified as toxic.

\section{RPE-choroid expression profile assessment}

Whole-transcriptome expression profiles were available from $126 \mathrm{RPE}$-choroid and 118 retina punches (each $6 \mathrm{~mm}$ in diameter) collected from the macular and extramacular regions of eyes derived from 66 human donors. These eyes were selected from a well-characterised repository derived from 3,903 donors and collected by G.S.H. over a 20-year period at the University of Iowa and St Louis University. Medical and ophthalmic histories, a family questionnaire and blood and sera were obtained from the majority of donors. Gross pathological features, as well as the corresponding fundus photographs and angiograms (when available) of all eyes in this repository were read and classified by retinal specialists. Fundi and/or posterior poles were graded using a slightly modified version of two standardised classification systems, as published previously., ${ }^{4,45-47}$ The ages of the donors ranged from nine to 101 years; approximately 50 per cent had documented clinical histories of AMD. RNA expression profiles were assessed using two-colour, $44 \mathrm{~K}$ Agilent wholegenome in situ oligonucleotide microarray analysis and a universal reference RNA experimental design. The universal reference RNA consisted of a 1:1 pool of RPE-choroid and retinal RNA generated from donors with and without AMD. After correcting for dye effects using Lowess normalisation, the net intensity values were determined and expressed as a percentage of the total array intensity. The ratios of the experimental and reference RNA signals were then calculated and the normalised percentage total of each experimental value was calculated by multiplication, using the geometric mean of all determinations of each probe's reference RNA value. For those probes with replicates in the array, the average values were determined. Inter-array differences were further corrected by quantile normalisation and probes that did not have net intensity values greater than six times the standard deviation of the background in at least 5 per cent of the samples were omitted. This resulted in a final dataset comprising 28,127 unique probes. Expression of the vitamin $D$ pathway-associated genes VDR, CYP27A1, CYP27B1 and CYP24A1 was examined.

\section{Investigation of vitamin $\mathrm{D}$ in human retinal cells}

To investigate vitamin D signalling in retinal cells, vitamin $\mathrm{D}$ was applied to retinoblastoma cells as a first iteration. Expression levels of mRNA were compared between untreated and treated cells by quantitative real-time polymerase chain reaction (qRT-PCR) analysis. Weri-RB1 (American Type Culture Collection [ATCC] catalogue number HTB 169) and Y79 (ATCC catalogue number HTB 18) were utilised for cell culture and subsequent treatment with vitamin D3. Cells were cultured in accordance with the manufacturer's specification/requirements. Cells were treated with $10 \mu \mathrm{M}$ Vitamin D3 (final concentration) for 1 
hour, 6 hours, 12 hours, 24 hours or 48 hours. Following the allotted treatment time, cells were then harvested. RNA isolated from these cells was used for qRT-PCR assays. For each gene tested, three technical replicates were used, with $1 \mu \mathrm{l}$ of cDNA being used in each well, with $5 \mu \mathrm{l}$ of SYBR ${ }^{\circledR}$ Green master mix (Invitrogen Corporation Carlsbad, CA, USA), $3 \mu \mathrm{l} \mathrm{dH}_{2} \mathrm{O}$ and $1 \mu \mathrm{l}$ of a forward/reverse mix of primers for a final primer concentration of $1 \mu \mathrm{M}$. The final reaction volume for each sample was $10 \mu \mathrm{l}$. Samples were run using an ABI 9600 platform (Life Technologies Corp, Carlsbad, CA, USA), for a total of 40 cycles, with readings being taken every cycle. Triplicates were averaged and the delta-Ct, compared with $\beta$-actin, was determined for each gene. Each triplicate reaction was performed for three separate RNA samples. Standard deviation was calculated for each dataset. Comparisons between time points and controls were made for fold-change estimation and relative expression, using the following formula: $1000 / 2^{\text {Delta-CtBactin-Delta-Cttestgene }}$.

\section{Genotyping analysis}

Genotyping was performed on leukocyte DNA that was purified by using standard phenol-chloroform or DNAzol (Invitrogen) extraction protocols. Initially, genotyping was performed with tagging SNPs (tagSNPs) from the vitamin D pathway genes CYP27A1, CYP27B1, VDR and CYP24A1. These particular genes were chosen because they are in regions of the genome previously reported by linkage studies to harbour AMD susceptibility loci. $^{36,48}$ CYP27A1 is located on chromosome 2q33-qter and spans approximately 34 kilobases (kb). CYP27B1 is located on chromosome 12q13.1-q13.3 and spans approximately $5 \mathrm{~kb}$. $V D R$ is located on chromosome 12q13.11 and spans $63 \mathrm{~kb}$. CYP24A1 is located on chromosome $20 \mathrm{q} 13$ and spans approximately $21 \mathrm{~kb}$. To assess variation within these genes, tagSNPs were chosen to span each gene using data from HapMap (http://www.hapmap.org/) and the following criteria: (i) the minor allele frequency was greater than 10 per cent; (ii) the $r^{2}$ value was at least 0.8 ; and (iii) SNPs tagged for at least six other SNPs. The location of SNPs with respect to introns/exons was analysed in terms of the largest coding transcript for each gene, as listed in Ensembl (http://www.ensembl.org/index.html) (Table S2). These SNPs were supplemented with additional SNPs, chosen to be evenly spaced along the length of the gene in an effort fully to capture variation within a given gene. In total, 59 SNPs were initially screened by Sequenom (San Diego, CA, USA) in the extremely discordant sibling pair discovery cohort (135 sibling pairs, 270 individuals): CYP27A1, $n=4$; VDR, $n=33$; CYP27B1, $n=2$; CYP24A1, $n=20$ (Table S2).

Multiplex PCR assays were designed using Sequenom SpectroDESIGNER software (version 3.0.0.3) by inputting sequence containing the SNP site and 100 base pairs (bp) of flanking sequence on either side of the SNP. Briefly, $10 \mathrm{ng}$ of genomic DNA was amplified in a $5 \mu l$ reaction containing $1 \times$ HotStar Taq PCR buffer (Qiagen, Valencia, CA, USA), $1.625 \mathrm{mM} \mathrm{MgCl}_{2}, \quad 500 \mu \mathrm{l}$ each dNTP, $100 \mathrm{nM}$ each PCR primer and $0.5 \mathrm{U}$ HotStar Taq (Qiagen). The reaction was incubated at $94^{\circ} \mathrm{C}$ for 15 minutes, followed by 45 cycles at $94^{\circ} \mathrm{C}$ for 20 seconds, $56^{\circ} \mathrm{C}$ for 30 seconds and $72^{\circ} \mathrm{C}$ for 1 minute, followed by another 3 minutes at $72^{\circ} \mathrm{C}$. Excess dNTPs were then removed from the reaction mixture by incubation with $0.3 \mathrm{U}$ shrimp alkaline phosphatase (USB Corporation, Cleveland, OH, USA) at $37^{\circ} \mathrm{C}$ for 40 minutes, followed by 5 minutes at $85^{\circ} \mathrm{C}$ to deactivate the enzyme. Single primer extension over the SNP was carried out in a final concentration of between $0.625 \mu \mathrm{M}$ and $1.5 \mu \mathrm{M}$ for each extension primer (depending on the mass of the probe), iPLEX termination mix (Sequenom) and 1.35 U iPLEX enzyme (Sequenom) and cycled using a two-step 200 short cycles programme; $94^{\circ} \mathrm{C}$ for 30 seconds, followed by 40 cycles at $94^{\circ} \mathrm{C}$ for 5 seconds, five cycles at $52^{\circ} \mathrm{C}$ for 5 seconds, $80^{\circ} \mathrm{C}$ for 5 seconds and then $72^{\circ} \mathrm{C}$ for 3 minutes. The reaction was then desalted by the addition of $6 \mathrm{mg}$ cation exchange resin, followed by mixing and centrifugation to settle the contents of the tube. The extension product was then spotted onto a 384-well SpectroCHIP before being flown in the matrix-assisted laser desorption/ionisation time-of-flight (MALDI-TOF) mass spectrometer. Data were collected, in real time, using 
SpectroTYPER Analyzer 3.3.0.15, SpectraAQUIRE 3.3.1.1 and SpectroCALLER 3.3.0.14 (Sequenom). Additionally, to ensure data quality, genotypes for each subject were checked manually.

In order to discover novel variation, a combination of direct sequencing and NextGen exon capture were performed. Oligonucleotide primers were selected using the Primer3 program (http:// primer3.sourceforge.net/) to encompass the SNP and flanking sequences (Table S3). All PCR assays were performed using genomic DNA fragments from $20 \mathrm{ng}$ of leukocyte DNA in a solution of $10 \times$ PCR buffer containing $25 \mathrm{mM} \mathrm{MgCl}_{2}$, $0.2 \mathrm{mM}$ each of dATP, dTTP, dGTP and dCTP, and 0.5 units of Taq DNA polymerase (USB). $5 \mathrm{M}$ betaine was added to the reaction mix for rs2414687 (Sigma-Aldrich, St Louis, MO, USA). The temperatures used during the PCR were as follows: $95^{\circ} \mathrm{C}$ for 5 minutes followed by 35 cycles of $58^{\circ} \mathrm{C}$ for 30 seconds, $72^{\circ} \mathrm{C}$ for 30 seconds and $95^{\circ} \mathrm{C}$ for 30 seconds, with a final annealing at $58^{\circ} \mathrm{C}$ for 1.5 minutes and extension of $72^{\circ} \mathrm{C}$ for 5 minutes. For sequencing reactions, PCR products were digested according to the manufacturer's protocol using ExoSAP-IT (USB) and were then subjected to a cycle sequencing reaction using the Big Dye Terminator v3.1 Cycle Sequencing kit (Applied Biosystems, Foster City, CA, USA), according to the manufacturer's protocol. Products were purified using Performa DTR Ultra 96-well plates (Edge Biosystems, Gaithersburg, MD, USA) in order to remove excess dye terminators. NextGen sequencing was performed on exonic regions using methods that have been previously described. ${ }^{49}$ For direct sequencing, samples were sequenced on an ABI Prism 3100 DNA sequencer (Applied Biosystems). Electropherograms generated from the ABI Prism 3100 were analysed using the Lasergene DNA and protein analysis software (DNASTAR, Inc., Madison, WI, USA). Electropherograms were read by two independent evaluators without knowledge of the subject's disease status. All patients were sequenced in the forward direction $\left(5^{\prime}\right.$ to $\left.3^{\prime}\right)$, unless variants or polymorphisms were identified, in which case confirmation was obtained in some cases by sequencing in the reverse direction.
For the genotyping of the variation discovered by direct and NextGen sequencing, a combination of direct sequencing and Taqman genotyping was employed to supplement data previously acquired by Sequenom or to investigate further variation. Direct sequencing was used to genotype the rs6022993, rs6091828, rs6127119, c.990 + 189 $\mathrm{G}>\mathrm{A}, \quad$ rs6127118 and c. $990+222 \_223$ ins 99 SNPs using a single set of primers: forward primer TGGACTGAGGTTTTCTTCTGTG and reverse primer GGCACATGAAGTCTCCTCCT. For all other SNPs, Taqman genotyping was employed. Briefly, either TaqMan Pre-Designed SNP Genotyping Assays or Custom TaqMan SNP Genotyping Assays kits (Applied Biosystems) were designed (for listing of SNPs and probes, see Table S4). The $40 \times$ stock of the probes were diluted to $16 \times$ with $0.5 \times$ tris-ethylenediamine tetra-acetic acid (EDTA) and stored at $-20^{\circ} \mathrm{C}$. The amplification reaction was carried out in a total reaction volume of $16.25 \mu \mathrm{l}$ containing $2.5 \mu \mathrm{l}$ DNA $(10 \mathrm{ng}), 1.25 \mu \mathrm{l}$ of $16 \times$ probe and $12.5 \mu \mathrm{l}$ of TaqMan Genotyping Master Mix. Sample DNA was amplified using the following reaction: 1 minute at $60^{\circ} \mathrm{C}, 10$ minutes at $95^{\circ} \mathrm{C}$ and 40 cycles of 15 seconds at $92^{\circ} \mathrm{C}$ and 1 minute at $60^{\circ} \mathrm{C}$. The amplification reaction was carried out on thermocyclers and then fluorescence was measured on the ABI 7500 Real-Time PCR System by which the genotypes are analysed with the accompanying software or, in some cases, manually.

\section{Statistical analysis}

Epidemiological data

Conditional logistic regression (CLR) (SAS 9.0, SAS Institute Inc., Cary, NC, USA) was performed to identify factors associated with neovascular AMD. Potential risk factors of interest, as defined above, were evaluated initially in single factor analysis. Numerical variables such as serum $25(\mathrm{OH}) \mathrm{D}$ levels and UV irradiance were tested as continuous variables, while other variables-including iris colour, skin cancer history, self-reported sun exposure and vitamin supplementation-were treated as categorical. In addition to smoking, known genetic risk 
variants in both $C F H$ and ARMS2/HTRA1 were controlled for. ${ }^{38,50-52}$ For these genetic variables, each SNP $(n=18)$ was tested under an additive genetic model, along with UV irradiance. The backward selection procedure in conditional logistic regression was used to create the most parsimonious statistical model predictive of neovascular AMD. Specifically, each variable was tested for its association with AMD and entered into the model if its $p$-value was less than 0.15 . Those variables that met these criteria were then kept in the model if the covariate-adjusted $p$-value was less than 0.1 . Using the variables selected in backward selection, a multiple variable model was constructed and tested for its association with neovascular AMD.

\section{Genotyping data}

SNPs were tested for association using the minor allele, as defined by the allele occurring less frequently in the normal subjects for all cohorts examined. Initial testing of association between the variation and AMD in the extremely discordant sibling pair was done using the family-based association test (FBAT) (http://biosun1.harvard.edu/ fbat/ fbat.htm) and generalised estimating equations (GEE), assuming an additive genetic model in SAS. For validation in the extended sibling cohort, allelic associations were performed in SAS (v9.1) using conditional logistic regression (CLR). For replication in the unrelated case-control cohorts, allelic associations were performed using unconditional logistic regression (UCLR) in SAS. Both analyses were performed assuming an additive genetic model and controlling for covariates (age, sex and smoking). All haplotypic associations were performed initially using FBAT in the discovery cohort and then for validation and replication using the program UNPHASED (http://www.mrc-bsu.cam.ac.uk/personal/frank/ software/unphased/). For the family data, the model for sibships was used. UNPHASED uses likelihood ratio association analysis, and for sibships uses nuclear families with missing parental genotype data. ${ }^{53}$ Covariates-specifically age, sex and smoking history-were controlled for in analysis using residuals, as calculated in $\mathrm{R}$ Statistical Software (http://www.r-project.org/).
Linkage disequilibrium (LD) ( $\mathrm{D}^{\prime}$ and $\left.r^{2}\right)$ between each of the SNPs was determined using Haploview (http://www.broad.mit.edu/mpg/haploview/). Deviation from Hardy-Weinberg equilibrium was tested on each SNP using the chi-square test in the unaffected population. Haplotype blocks were constructed in Haploview using the method proposed by Gabriel et al. ${ }^{54}$ Haplotype blocks defined by the Gabriel rule were tested for association with all subtypes of AMD using UNPHASED, and additionally FBAT in the families. In addition to the use of residuals, multiple testing in FBAT was corrected for using the permutation test. Haplotype testing was also performed by two additional methods, backward selection and sliding window. Backward selection was performed in UNPHASED, beginning with all SNPs with association $p$ value $\leq 0.12$ in the model and taken out one at a time in order to determine the most significantly parsimonious haplotype. ${ }^{55}$ Sliding window analysis was also performed in UNPHASED, using a window size of 2 and using all SNPs with association $p \leq 0.12$. Genotype and allele frequencies for all SNPs identified as either individually significant or significant as part of a haplotype were calculated in the affected patients and separately in unaffected controls (Table S4).

Based on the variation found within the extended sibling cohort, replication was performed on a cohort of unrelated cases and controls from central Greece and the combined NHS and HPFS cohort. Meta-analysis of all four cohorts was performed for SNPs genotyped in all four cohorts and also significant haplotypes using the Comprehensive Meta-Analysis v2 (Biostat, Englewood NJ, USA) program. Z-scores and overall $p$-values for each SNP were calculated under a fixed model based on odds ratios obtained from CLR for the family-based cohorts and UCLR for the case-control cohorts calculated in SAS while controlling for the covariates age, sex and smoking history. To test for the effects of population heterogeneity, Cochran's $Q$ was also calculated, which is the weighted sum of squared differences between individual study effects and the pooled effect across studies. 
In order to test for interaction or epistasis between the genes investigated here and previously reported AMD-associated genes, an interaction term was added into the regression model, including both variables. SNPs included in statistical analyses were SNPs that had been genotyped in more than one cohort: VDR (rs2189480); CFH (rs572515 and rs1061170); ARMS2/HTRA1 (rs10490924, rs11200638 and rs1049331); and RAR-related Orphan receptor A gene $(R O R A$; rs12900948 and rs4335725). ${ }^{38,40,42,51,52}$ An additional pooled caseonly analysis was performed in logistic regression to test for interaction with greater power. Statistical interaction was also tested for between UV measures and the variants examined using an interaction term in the regression models.

\section{Bioinformatic analysis of functional implications of genetic variants}

Variants were analysed by computational methods to infer potential functional relevance. Conservation analysis was performed using the comparative genomics feature in Ensembl (http://useast.ensembl.org/ index.html) to compare the human variant with nine eutherian mammals, including chimp, mouse and pig. To analyse the putative biological effects of each exonic or intronic variation, either the major or minor allele was input into predictive programs flanked on either side by $100 \mathrm{bp}$ of sequence. Potential human transcription factor binding sites were analysed using default parameters of the transcription element search system from the University of Pennsylvania (http://www.cbil.upenn.edu/ cgi-bin/tess/tess). Additional analysis of putative splice sites was performed using the default parameters of the Alternative Splice Site Predictor (http://www.es.embnet.org/ mwang/assp.html). Also, the publicly available program mRNA by SNP Browser v 1.0.1 ${ }^{56,57}$ was used to investigate the association of significant CYP24A1 SNPs and expression quantitative trait loci (eQTLs).

\section{Pathway analyses}

We used Ingenuity Pathway Analysis (IPA) software (http://www.ingenuity.com/) to create a visual representation of the complex shared pathways involved in the aetiology of AMD, the metabolism/ synthesis of vitamin D and the vascularisation processes. The likelihood that each gene/protein is randomly associated with a given function, pathway or other protein/gene is automatically calculated using the right-tailed Fisher's exact test. We accepted only those relationships with $p>0.0001$, suggesting that their association with our gene/ protein functions or diseases was non-random.

\section{Results}

\section{Patient population}

For our initial discovery cohort, we recruited a total of 135 extremely discordant sibling pairs (one sibling with neovascular AMD and one unaffected sibling - AREDS category 1 or less). The mean $\pm \mathrm{SD}$ age of the unaffected siblings was $76.0 \pm 7.6$ years (age range, 50.3-93.9) and the mean \pm SD of the affected (neovascular) siblings was $71.7 \pm 8.0$ years (age range, 49.0-86.5) (Table S1). Of the affected patients, 47 per cent were male and 39 per cent of the matching unaffected siblings were male. Most participants were of European descent.

The expanded sibling cohort comprised 481 sibling pairs and 657 individuals: 198 unaffected controls, 106 early and intermediate dry AMD patients (AREDS category 2 and 3), and 353 neovascular AMD patients (Table S1). The mean \pm SD age of the unaffected subjects was $75.4 \pm 8.3$ years (age range, 50.3-94.3 years), the mean age of the patients with early or intermediate AMD was $77.6 \pm 7.2$ years (age range, 58.2-100.6 years), and the age of those subjects with neovascular AMD was $73.9 \pm 7.8$ years (age range, 49.0-94.0 years). Forty-four percent of the unaffected subjects, 35 per cent of the AREDS category 2 and 3 AMD subjects and 41 per cent of the neovascular subjects were male. The cohort from central Greece consisted of a total of 344 patients: 121 unaffected controls, 84 early and intermediate dry AMD patients (AREDS category 2 and 3) and 139 neovascular AMD patients (Table S1). The mean \pm SD age of the unaffected subjects was $73.5 \pm 7.3$ years (age range, $48.0-88.0$ years), the age of the patients 
with early or intermediate AMD was $74.5 \pm 7.8$ years (age range, 52.0-91.0 years) and the mean age of those subjects with neovascular AMD was $76.2 \pm 7.5$ years (age range, 49.0-94.0 years). Fifty-one per cent of the unaffected subjects, 44 per cent of the AREDS category 2 and 3 AMD subjects and 45 per cent of the neovascular subjects were male. All participants were white and from central Greece.

The prospective cohorts from the NHS and HPFS consisted of a total of 1,527 patients: 1,070 unaffected controls, 293 early and intermediate dry AMD patients (AREDS category 2 and 3) and 164 AMD neovascular patients. The mean \pm SD age of the unaffected subjects was $60.2 \pm 5.9$ years (age range, $41.3-74.0$ years), the age of the patients with early or intermediate AMD was $59.5 \pm 5.7$ years (age range, 41.3-74.0 years) and the mean age of those subjects with neovascular AMD was $61.1 \pm$ 6.0 years (age range, 42.7-74.0 years). Thirty-six per cent of the unaffected subjects, 18 per cent of the AREDS category 2 and 3 AMD subjects and 46 per cent of the neovascular subjects were male.

\section{Analysis of sunlight-associated epidemiological factors}

The analysis of epidemiological data was performed on 133 extremely discordant sibling pairs, equalling 266 subjects. Twenty-six affected patients (19.5 per cent) had skin cancer and 25 (18.8 per cent) of their matched unaffected siblings also had skin cancer. Iris colour in the affected patients was 42.9 per cent blue $(n=151), 24.8$ per cent green $(n=33)$ and 32.3 per cent brown $(n=34)$. In the matched unaffected patients iris colour was 41.6 per cent blue $(n=132), 25.0$ per cent green $(n=33)$ and 33.4 per cent brown $(n=45)$. Of the affected siblings, 94 (70.6 per cent) reported taking multivitamin supplements at least twice a week for at least six months and 76 (57.1 per cent) of the unaffected patients reported the same. Specific vitamin D supplementation was reported in 11 affected patients $(8.3$ per cent) and 15 unaffected patients (11.3 per cent).

The average yearly UV index in the affected patients was $5.24 \mathrm{~W} / \mathrm{m}^{2}$ (range, 4.42-7.49) and
$5.43 \mathrm{~W} / \mathrm{m}^{2}$ (range, 4.37-7.49) in the unaffected patients. Average yearly UVA in the affected patients was $40.22 \mathrm{~W} / \mathrm{m}^{2}$ (range, 36.16-50.58) and 41.17 $\mathrm{W} / \mathrm{m}^{2}$ (range, 36.17-50.57). Average yearly UVB in the affected patients was $0.99 \mathrm{~W} / \mathrm{m}^{2}$ (range, $0.84-1.41$ ) and $1.03 \mathrm{~W} / \mathrm{m}^{2}$ (range, $0.84-1.41$ ) in the unaffected patients.

Single CLR regression showed that, of these factors, UV, UVA and UVB irradiance were the risk factors most significantly associated with neovascular AMD (Table 1) $(p=0.0013$ for all). Analysis of self-reported sun exposure suggested a protective effect for those who reported minimal sun exposure 15 years in the past $(p=0.04)$; however, this did not remain significant after correction for multiple testing. Skin cancer status, iris colour, vitamin D supplementation and various exposures of sunlight were not associated with neovascular AMD risk in CLR analysis.

The backward selection model using previously reported SNPs (12 in CFH and six in ARMS2/ HTRA1), smoking history and yearly UV irradiance showed that the model most predictive of neovascular AMD included smoking greater than ten pack-years, CFH rs572515, HTRA1 rs1049331, and total UV index, UVA irradiance or UVB irradiance (data not shown). Each UV irradiance measure was shown to be significant in the multiple model $(p=0.01$ for all). Most significantly, for every one-unit increase in UV index between 4.73 and 7.49, AMD risk was reduced 66.6-fold after controlling for smoking, CFH rs572515 and HTRA1 rs1049331 (Table 2).

\section{Analysis of serum levels of vitamin D}

Serum 25(OH)D levels were measured for 100 patients comprising 50 extremely discordant sibling pairs. Of the 50 unaffected siblings, 30 took multivitamins, five took both multivitamins and vitamin D supplements and one took vitamin D supplements alone. The mean $\pm \mathrm{SD}$ serum $25(\mathrm{OH}) \mathrm{D}$ levels in affected patients was $24.7 \pm 10.5 \mathrm{ng} / \mathrm{ml}$ (concentration range, $5.1-49.6 \mathrm{ng} / \mathrm{ml}$ ) and in unaffected patients was $27.5 \pm 10.7 \mathrm{ng} / \mathrm{ml}$ (concentration range, $8.9-67.3 \mathrm{ng} / \mathrm{ml})$. Serum $25(\mathrm{OH}) \mathrm{D}$ 
levels were not statistically different when comparing affected and unaffected siblings $(p=0.22)$ (Figure 1), or when controlling for the month in which serum was collected.

\section{RPE-choroid expression analysis}

Of the vitamin D pathway-associated genes examined in a whole transcriptome analysis of ocular tissues derived from 66 human donors, no

Table I. Single factor analysis of epidemiological factors using conditional logistic regression

\begin{tabular}{|c|c|c|c|c|c|}
\hline \multirow[b]{2}{*}{ Risk factor } & \multirow[b]{2}{*}{$\begin{array}{l}\text { Odds ratio }(95 \% \\
\text { confidence } \\
\text { interval) }\end{array}$} & \multirow[b]{2}{*}{$p$-Value } & \multicolumn{3}{|c|}{$\begin{array}{l}\text { Distribution of continuous } \\
\text { variables (if applicable) }\end{array}$} \\
\hline & & & Average & Min & Max \\
\hline $\begin{array}{l}\text { Vitamin D supplements for } \geq 6 \\
\text { months }\end{array}$ & $0.862(0.505-1.472)$ & 0.5866 & & & \\
\hline $\begin{array}{l}\text { Multivitamin supplements for } \geq 6 \\
\text { months }\end{array}$ & $0.667(0.237-1.873)$ & 0.4417 & & & \\
\hline Serum 25(OH)D level (ng/ml) & $0.973(0.934-1.013)$ & 0.1859 & 26.10 & 5.10 & 67.30 \\
\hline Blue eyes & $1.064(0.654-1.731)$ & 0.8039 & & & \\
\hline Green eyes & $1.000(0.573-1.744)$ & 1.0000 & & & \\
\hline Brown eyes & $0.966(0.579-1.613)$ & 0.8960 & & & \\
\hline Skin cancer & $1.050(0.570-1.933)$ & 0.8762 & & & \\
\hline Sun exposure now $\mathrm{I}^{\dagger}$ & I.07I (0.5I7-2.220) & 0.8528 & & & \\
\hline Sun exposure now $2^{\dagger}$ & $1.350(0.757-2.407)$ & 0.3090 & & & \\
\hline Sun exposure now $3^{\dagger}$ & $0.929(0.545-1.584)$ & 0.7856 & & & \\
\hline Sun exposure now $4^{\dagger}$ & $0.750(0.407-1.382)$ & 0.3562 & & & \\
\hline Sun exposure now 1 or $2^{\dagger}$ & $1.381(0.788-2.42 I)$ & 0.2600 & & & \\
\hline Sun exposure 15 years ago $\mathrm{I}^{\dagger}$ & $0.955(0.525-1.736)$ & 0.8788 & & & \\
\hline Sun exposure 15 years ago $2^{\dagger}$ & $1.333(0.83 I-2.14 \mid)$ & 0.2336 & & & \\
\hline Sun exposure 15 years ago $3^{\dagger}$ & $1.045(0.583-1.876)$ & 0.8815 & & & \\
\hline Sun exposure 15 years ago $4^{\dagger}$ & $0.375(0.147-0.958)$ & 0.0405 & & & \\
\hline Sun exposure 15 years ago 1 or $2^{\dagger}$ & $1.409(0.816-2.433)$ & 0.2186 & & & \\
\hline Year UV index (TUV) ${ }^{\ddagger}$ & $0.115(0.031-0.432)$ & 0.0013 & 5.33 & 4.37 & 7.49 \\
\hline Year UV-A (TUV) & $0.619(0.463-0.829)$ & 0.0013 & 40.69 & 36.16 & 50.58 \\
\hline Year UV-B (TUV) & $0.009(0.008-0.010)$ & 0.0013 & 1.01 & 0.84 & 1.41 \\
\hline Year UV index (EPA) $)^{\S}$ & $0.104(0.020-0.54 I)$ & 0.0071 & 4.13 & 1.00 & 10.00 \\
\hline
\end{tabular}


Table 2. Multiple conditional logistic regression for UV irradiance

\begin{tabular}{|c|c|c|}
\hline Risk factor & Odds ratio $(95 \% \mathrm{Cl})$ & $p$-Value \\
\hline Year UV index & $0.015(0.001-0.433)$ & 0.0143 \\
\hline Smoking $\geq 10$ pack-years & $3.581(1.590-8.063)$ & 0.0021 \\
\hline CFH rs5725I5 (additive model) & 7.971 (2.960-21.459) & 3.99E-05 \\
\hline HTRA I rsI04933I (additive model) & $9.829(3.589-26.920)$ & 8.77E-06 \\
\hline Risk factor & Odds ratio $(95 \% \mathrm{Cl})$ & p-Value \\
\hline Year UV-A & $0.368(0.163-0.828)$ & 0.0157 \\
\hline Smoking $\geq 10$ pack-years & $3.705(1.63|-8.4| 8)$ & 0.0018 \\
\hline CFH rs5725I5 (additive model) & $8.403(3.057-23.098)$ & 3.69E-05 \\
\hline HTRAI rsI04933I (additive model) & 9.969 (3.618-27.467) & 8.72E-06 \\
\hline Risk factor & Odds ratio $(95 \% \mathrm{CI})$ & $p$-Value \\
\hline Year UV-B & $0.009(0.000-0.011)$ & 0.0153 \\
\hline Smoking $\geq 10$ pack-years & $3.606(1.597-8.141)$ & 0.0020 \\
\hline CFH rs5725I5 (additive model) & $8.084(2.985-21.895)$ & $3.93 \mathrm{E}-05$ \\
\hline HTRAI rsI04933I (additive model) & $9.869(3.598-27.073)$ & 8.73E-06 \\
\hline
\end{tabular}

Abbreviation: $\mathrm{Cl}$, confidence interval.

significant association as a function of age or disease status was observed; however, differences in expression levels between the macular and extramacular regions were observed. Expression of both $V D R$ and CYP27A1 was detected in the RPEchoroid; CYP27A1 and CYP27B1 were detected in the retina. CYP27A1 was expressed at low to

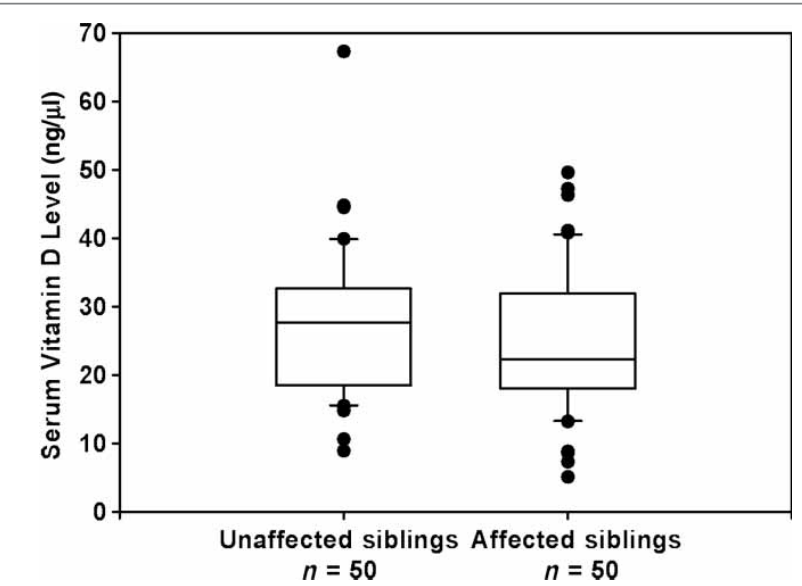

Figure I. Analysis of serum levels of vitamin D in extremely discordant sibpairs. moderate levels, with significant differences detected between the extramacula and macula regions (Figure 2A). Similar differences in the extramacula:macula expression ratio of CYP27A1 were observed in both non-AMD (1.5-fold, $p=$ 0.00012; one-tailed Mann-Whitney $U$ test) and AMD (1.7-fold, $\left.p=5 \times 10^{-8}\right)$ RPE-choroids. Similar macula:extramacula expression differences were observed for CYP27A1 (Figure 2C) and CYP27B1 (Figure 2D) in the retina. $V D R$ expression in many RPE-choroid tissues was at or below the level of detection, but was observed at significantly higher levels in several donors, concomitant with an increased expression of genes involved in local inflammatory responses (M.J. Radeke, D.H. Anderson and L.V. Johnson, personal communications). There was a trend of slightly higher VDR expression in the macular region of both normal and diseased RPE-choroids (1.3- and 1.5-fold, respectively) which rose to a level of significance $(p=0.02)$ in the diseased RPE-choroid (Figure $2 \mathrm{~B})$, but not the retina (data not shown). 


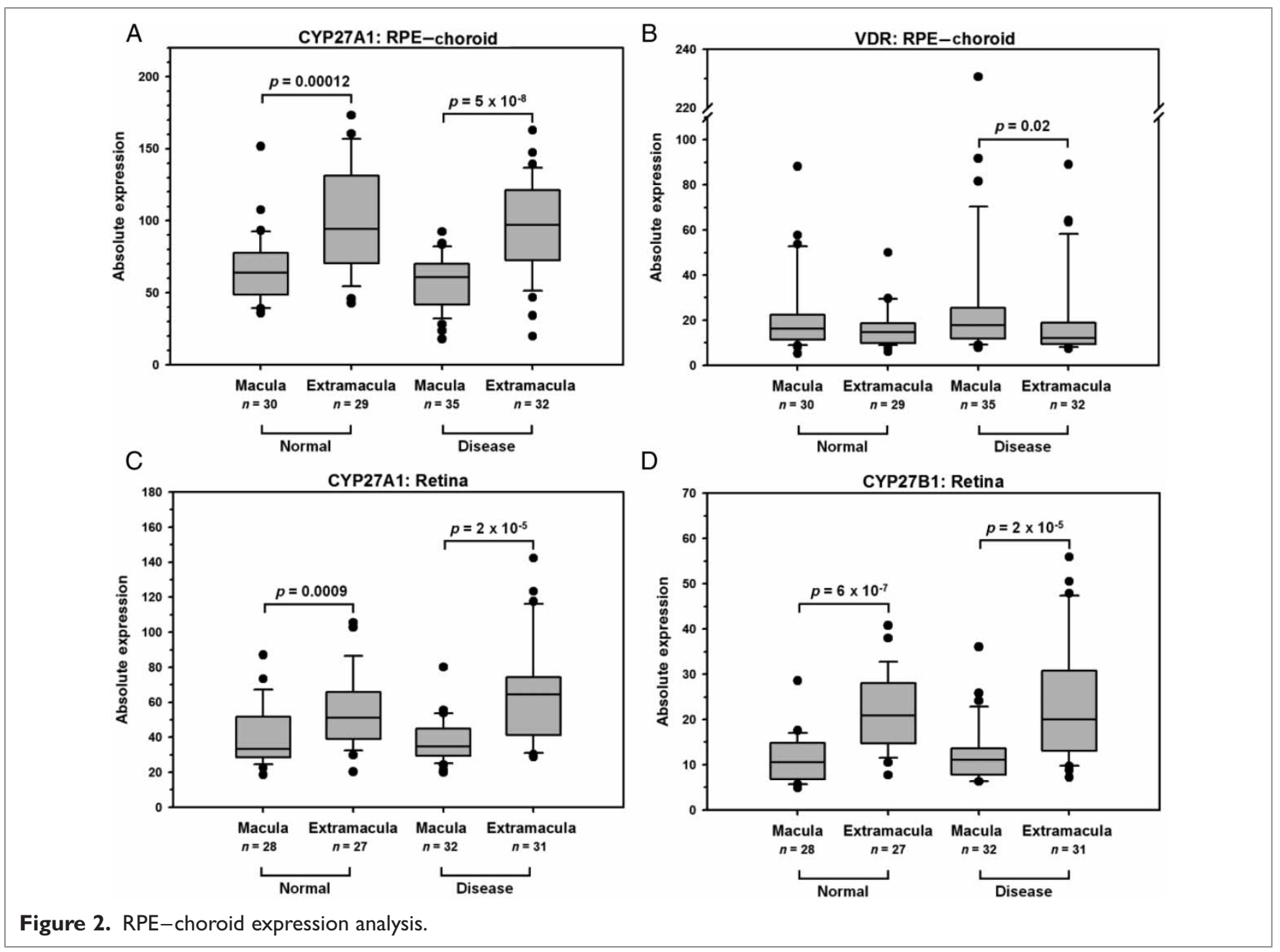

\section{Investigation of vitamin $\mathrm{D}$ in retinal cells}

Both cell lines were derived from a human retinoblastoma; however, they were isolated and deemed continuous at two separate institutions. As both cell lines were derived from a retinoblastoma, and with previous studies implicating vitamin D3 as a potential therapeutic agent for this cancer, ${ }^{58}$ a subset of genes involved in the vitamin D3 pathway were selected for testing via qRT-PCR. Vitamin D treatment of retinoblastoma cells did not result in significant changes in mRNA expression of any of the genes investigated. The genes tested by qRT-PCR were CYP24A1 and the calreticulin gene (CALR). For these two genes, vitamin D3 treatment resulted in gene expression changes of varying degrees in both cell lines. A general increasing trend was noted for CYP24A1, with peak expression occurring at the 48-hour time point in Weri-RB1-RB1-RB1 cells. By contrast, the Y79 cells exhibited a similar increasing trend, with peak expression at six hours, but then followed by a drastic decrease which remained until the final time point at 48 hours. CALR exhibited a pattern of an initial increase in expression, followed by a subsequent decrease and then a gradual increase over the subsequent time points. In Weri-RB1 cells, this was accompanied by peak expression at the final time point, while in Y79 cells the subsequent decrease occurred later, with no subsequent increase being noted owing to the decrease in expression occurring at the final time point at 48 hours. It would have been interesting to see if expression began to increase at later time points, as it did in Weri cells (see Figure 3). 


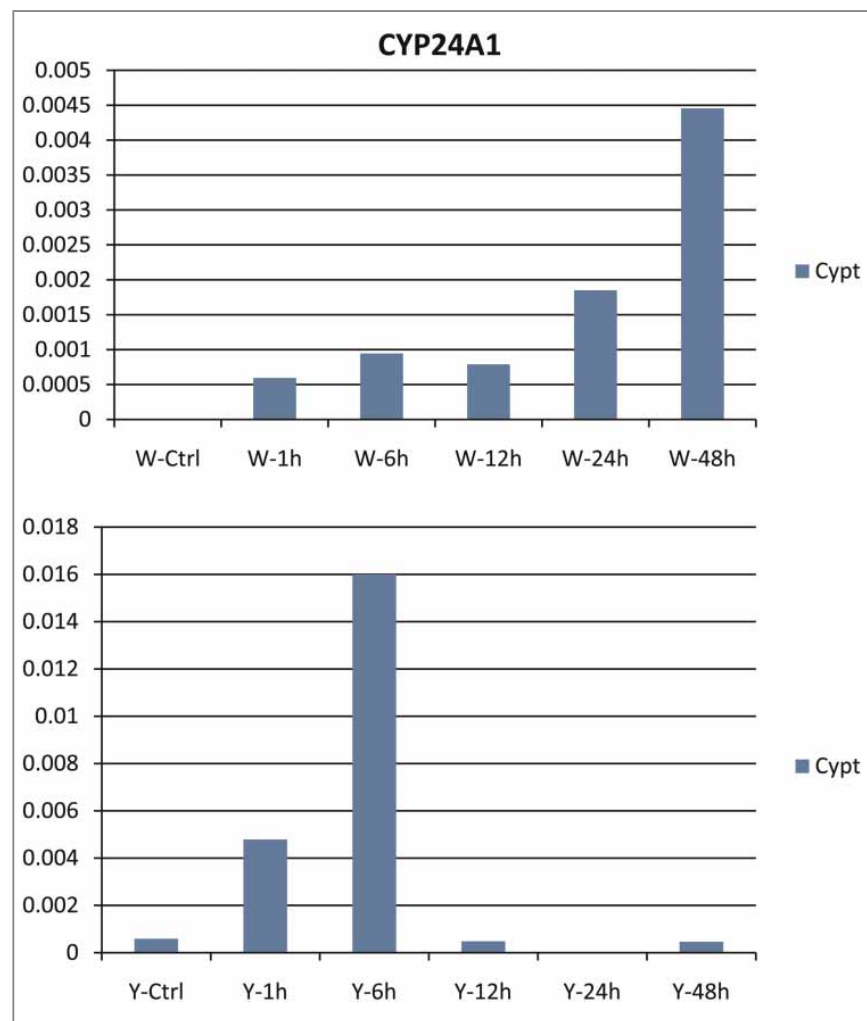

Figure 3. Vitamin D treatment.

\section{Analysis of CYP27A1, CYP27B1, VDR and $C Y P 24 A 1$ SNPs in the extremely discordant sibling pair cohort: Discovery cohort}

No significant deviations from Hardy-Weinberg equilibrium were observed for any of the variants studied in VDR, CYP27A1, CYP27B1 and $C Y P 24 A 1$ in unaffected siblings. Of the four genes tested, variation within both $V D R$ and CYP24A1 were found to be significantly associated with neovascular AMD. In VDR, rs2189480 (intron 4) was found to be significantly associated with risk of neovascular AMD by FBAT $(p=0.02)$ (Table 3$)$. In FBAT, the minor alleles of CYP24A1 rs6127118 (intron 7) and rs2762934 (exon 12) were found to be associated with risk of neovascular AMD ( $p=$ 0.03 and $p=0.01)$. Two haplotype blocks were shown to be significantly associated with neovascular AMD risk in FBAT (Figure 4). In block 4, comprising rs6068816 (exon 6) and rs6127118 (intron 7), haplotype h1 (GC) was modestly significant $(p<0.03)$ and haplotype h2 (GT) was significant under an additive model $(p=0.002)$. In block 5, comprising rs1570669 (intron 9), rs927650 (intron 11) and rs2762934 (exon 12), haplotype h3 (TGT) was significantly associated $(p=0.01)$. Due to the fact that these haplotypes were more significantly associated with AMD than any single SNP alone, and that there is more power to detect an association through haplotypes, ${ }^{59}$ we used these regions to drill down in the replication and validation cohorts.

\section{Sequencing of area surrounding significant variation}

Based on the initial findings of significant variation within $V D R$ and CYP24A1, a combination of direct sequencing and NextGen sequencing was performed on 95 neovascular patient samples in order to capture variation beyond the significantly associated tagging SNPs to include exons and surrounding exon/intron borders. Specifically, exons 4 and 5 of $V D R$ and exons 4-12 of CYP24A1 were assayed for variation. No further variation was found within $V D R$, but the following 22 SNPs were found in the regions investigated in CYP24A1: rs2296241, rs4809960, rs4809959, rs2181874, rs6068816, rs6022993, rs6091828, rs6127119, rs6127118, rs2296239, rs2274130, rs1570670, rs1977297, rs1570669, rs927650, rs2762934, rs4809957, rs6022987, rs11907350, rs10623012, rs4811494 and rs2762933 (see Table S2). Additionally, novel variations were found within CYP24A1 intron 7 at c. $990+189$ (chromosome 20: 52,779,066; G>A) and c.990 + 222-223 (chromosome 20: 52,779,033; an insertion of $99 \mathrm{bp}$ of the sequence GCGCACAGCATCTATACCACGGT GCCTCAGCGCACGGCCTCATACTAGACACCA CGGTGCCTCCGCGCACGGCCTCATACCAG ACGCCACGGTGCCTCC). Both variants were confirmed by sequencing in the reverse direction.

Further direct sequencing showed the $99 \mathrm{bp}$ insert to be a repeated sequence. Patients were found to be both homozygous and heterozygous for this repeat. Interestingly, an alternative heterozygote was found that consisted of one $99 \mathrm{bp}$ repeat and a second, smaller insert. This second insert had the same sequence as that described for rs3831062 but at a different location than that initially described (chromosome 20: 52,779,033; an insertion of $35 \mathrm{bp}$ 
Table 3. Family-based association test analysis of individual CYP27AI, CYP27BI, VDR and CYP24AI SNPs in discovery cohort

\begin{tabular}{|c|c|c|c|c|c|}
\hline Marker & Allele & Frequency & $\begin{array}{l}\text { Informative } \\
\text { families }\end{array}$ & $\begin{array}{c}Z \\
\text { score }\end{array}$ & p-Value \\
\hline \multicolumn{6}{|l|}{ CYP27AI } \\
\hline rs7594289 & G & 0.428 & 51 & -0.808 & 0.4189 \\
\hline rs7566656 & A & 0.485 & 60 & 1.179 & 0.2383 \\
\hline \multicolumn{6}{|l|}{ CYP27BI } \\
\hline rs8I76345 & $A$ & 0.030 & $<2$ & 0.000 & 1.0000 \\
\hline rs4646536 & C & 0.324 & $<2$ & 0.000 & 1.0000 \\
\hline \multicolumn{6}{|l|}{ VDR } \\
\hline rs45I6035 & G & 0.443 & 47 & 1.116 & 0.2643 \\
\hline rs7299460 & A & 0.262 & 36 & 1.333 & 0.1824 \\
\hline rs 10783219 & A & 0.361 & 42 & -0.630 & 0.5287 \\
\hline rs7|36534 & A & 0.238 & 35 & 1.622 & 0.1048 \\
\hline rsII574026 & $\mathrm{T}$ & 0.120 & 23 & 0.626 & 0.5316 \\
\hline rsII574027 & $\mathrm{T}$ & 0.017 & 2 & 1.414 & 0.1573 \\
\hline rs4237855 & $\mathrm{T}$ & 0.490 & 47 & -0.329 & 0.7419 \\
\hline rs4328262 & A & 0.568 & 49 & 0.956 & 0.3390 \\
\hline rs III68287 & C & 0.485 & 56 & -0.570 & 0.5688 \\
\hline rs4760648 & A & 0.447 & 52 & -0.640 & 0.5221 \\
\hline rs2853564 & C & 0.395 & 46 & 0.000 & 1.0000 \\
\hline$r s 2238136$ & A & 0.283 & 43 & -1.000 & 0.3173 \\
\hline rs2254210 & $\mathrm{T}$ & 0.369 & 54 & 0.843 & 0.3994 \\
\hline rs 10735810 & $\mathrm{~T}$ & 0.374 & 48 & 0.739 & 0.4602 \\
\hline rs10875693 & $A$ & 0.679 & 46 & 0.000 & 1.0000 \\
\hline rs2239186 & C & 0.248 & 44 & -0.137 & 0.8907 \\
\hline rs3782905 & G & 0.282 & 34 & -0.152 & 0.8788 \\
\hline rs3819545 & C & 0.427 & 54 & 0.226 & 0.8208 \\
\hline rs2189480 & C & 0.593 & 45 & -1.807 & 0.0707 \\
\hline rs 12721370 & $\mathrm{~T}$ & 0.112 & 15 & 1.414 & 0.1573 \\
\hline rs|27|799| & G & 0.564 & 51 & 0.000 & 1.0000 \\
\hline rs2239179 & G & 0.349 & 47 & -0.911 & 0.3621 \\
\hline rs2283342 & C & 0.205 & 38 & -0.302 & 0.7630 \\
\hline
\end{tabular}


Table 3. Continued

\begin{tabular}{|c|c|c|c|c|c|}
\hline Marker & Allele & Frequency & $\begin{array}{l}\text { Informative } \\
\text { families }\end{array}$ & $\begin{array}{c}Z \\
\text { score }\end{array}$ & p-Value \\
\hline rs210730I & $\mathrm{T}$ & 0.340 & 46 & 0.405 & 0.6858 \\
\hline rs2239182 & G & 0.420 & 46 & 0.788 & 0.4308 \\
\hline rsII574077 & G & 0.028 & 10 & -0.632 & 0.5271 \\
\hline rsIII 68267 & $\mathrm{~T}$ & 0.116 & 17 & 0.728 & 0.4669 \\
\hline rs7975I 28 & $\mathrm{~T}$ & 0.333 & 45 & 0.132 & 0.8946 \\
\hline rs I5444I0 & A & 0.337 & 46 & -0.640 & 0.5221 \\
\hline rs7975232 & $\mathrm{T}$ & 0.494 & 52 & 0.239 & 0.8111 \\
\hline rs731236 & C & 0.320 & 45 & -0.775 & 0.4386 \\
\hline rs3847987 & $\mathrm{T}$ & 0.150 & 28 & 1.029 & 0.3035 \\
\hline \multicolumn{6}{|l|}{ CYP24AI } \\
\hline rs2248359 & A & 0.425 & 49 & -0.611 & 0.5413 \\
\hline rs6022999 & C & 0.250 & 42 & -1.089 & 0.2763 \\
\hline rs 2585428 & A & $0.44 I$ & 56 & -0.342 & 0.7324 \\
\hline rs 2245153 & G & 0.201 & 48 & 1.089 & 0.2763 \\
\hline rs4809960 & G & 0.229 & 51 & 1.192 & 0.2332 \\
\hline rs4809959 & C & 0.500 & 46 & 0.122 & 0.9028 \\
\hline rs2181874 & $\mathrm{T}$ & 0.247 & 45 & -1.633 & 0.1025 \\
\hline rs3787557 & G & 0.144 & 40 & 1.265 & 0.2059 \\
\hline rs3787555 & $\mathrm{T}$ & 0.263 & 42 & 1.260 & 0.2076 \\
\hline rs3787554 & $\mathrm{T}$ & 0.065 & 20 & 0.209 & 0.8348 \\
\hline rs4809958 & C & 0.128 & 25 & 1.134 & 0.2568 \\
\hline rs2762939 & G & 0.275 & 36 & -0.816 & 0.4142 \\
\hline rs6068816 & $A$ & 0.079 & 22 & 0.000 & 1.0000 \\
\hline rs6127II8 & $\mathrm{T}$ & 0.157 & 22 & 2.132 & 0.0330 \\
\hline rs22093।4 & G & 0.256 & 43 & -1.387 & 0.1655 \\
\hline rs 1570669 & C & 0.335 & 45 & 0.630 & 0.5287 \\
\hline rs927650 & G & 0.511 & 44 & -0.391 & 0.6961 \\
\hline rs2762934 & $\mathrm{T}$ & 0.156 & 29 & -2.535 & 0.0112 \\
\hline rs6097807 & C & 0.241 & 50 & -1.131 & 0.2579 \\
\hline rs6068810 & A & 0.059 & 17 & 0.728 & 0.4669 \\
\hline
\end{tabular}




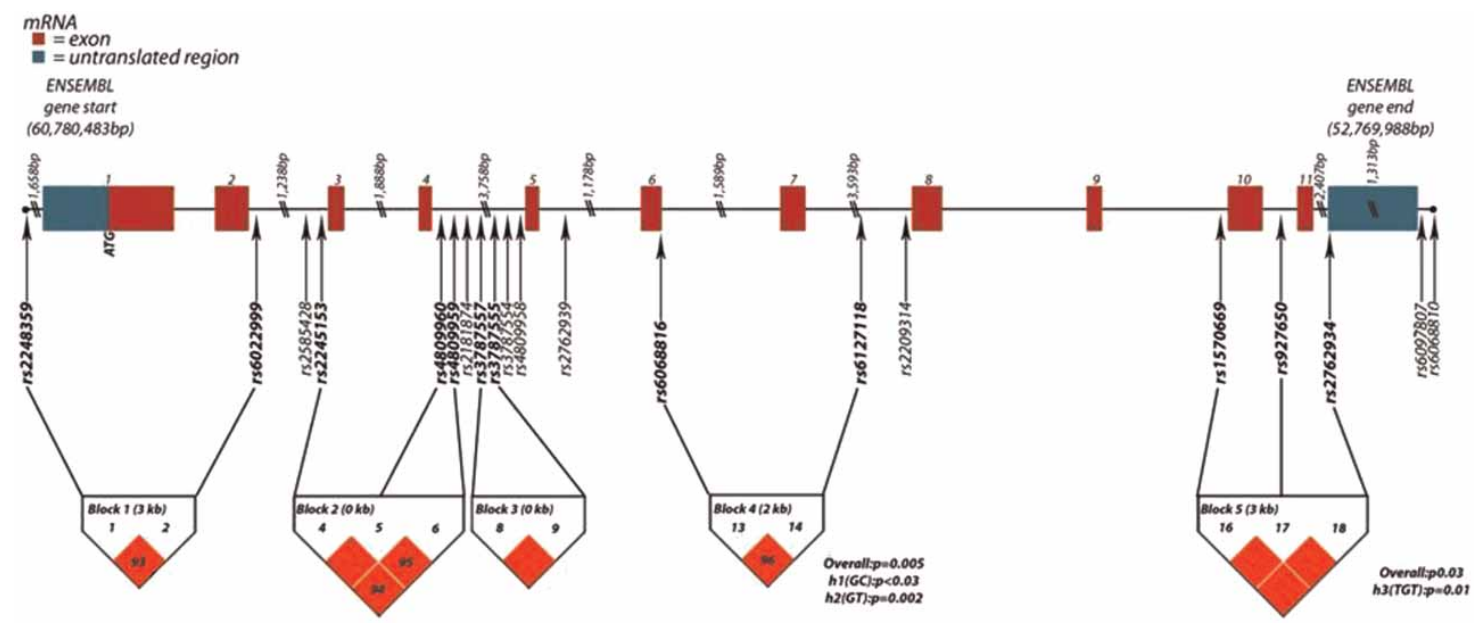

Figure 4. Significant CYP24AI haplotypes in discovery cohort.

of the sequence GGAGGCACCGTGGCGTCTG GTATGAGGCCGTGCGC). Direct sequencing was performed for all subsequent variation of this sequence. This $99 \mathrm{bp}$ insertion was not associated with AMD in either the sibling cohort or the Greek cohort.

\section{Analysis of $V D R$ and $C Y P 24 A 1$ SNPs in the replication cohorts}

Based on the results of direct sequencing, 24 SNPs/ structural variants were genotyped in the extended sibling cohort consisting of 657 individuals/481 sibling pairs and the unrelated case-control cohort from central Greece by a combination of Sequenom, Taqman and direct sequencing. Based on the preliminary findings of association in the discovery and expanded sibling cohorts, the following 12 SNPs were genotyped in the NHS/HPFS cohort: VDR rs2189480, CYP24A1 rs2181874, rs6127118, c.990 + 222-223ins99, rs2296239, rs2274130, rs1570670, rs1570669, rs927650, rs2762934, rs4809957 and rs11907350.

\section{Haplotype analysis of CYP24A1}

Haploview, using haplotype blocks defined by the Gabriel rule, ${ }^{54}$ demonstrated that in the extended sibling cohort there were four haplotype blocks spanning the more than 16,000 base pairs covered by genotyping (Figure 5). Of these haplotype blocks, none was shown to be significantly associated with any subtype of AMD risk by either FBAT analysis or UNPHASED analysis (data not shown). Similar results were found for the Greek cohort and the NHS/HPFS in UNPHASED (data not shown).

Those CYP24A1 SNPs that were shown to have a $p$-value $\leq 0.12$ in the analysis of individual SNPs using UNPHASED were analysed in a backward selection fashion and, additionally, by using a sliding window approach for haplotype association using the same program. In each of the four cohorts, no method identified significant haplotypes (data not shown).

\section{Meta-analysis of $V D R$ and CYP24A1}

Comprehensive meta-analysis v2 was used to analyse the variation which had been genotyped in all populations. VDR rs2189480 was not significantly associated with AMD. Several SNPs within CYP24A1 were shown to be significant by meta-analysis. When comparing all AMD with unaffected patients, rs1570669, rs1570670, rs2274130, rs2296239 and rs4809957 were all significantly associated with AMD $(p=0.0005, p=$ $0.02, p=0.008, p=0.02$ and $p=0.03$, respectively). For each of these SNPs, the overall $p$-value obtained by meta-analysis was more significant than that for each of the cohorts analysed where, in some cases, these SNPs were not individually significant (Table 4). Cochran's Q, the measure of heterogeneity, was significant for SNP rs927650 


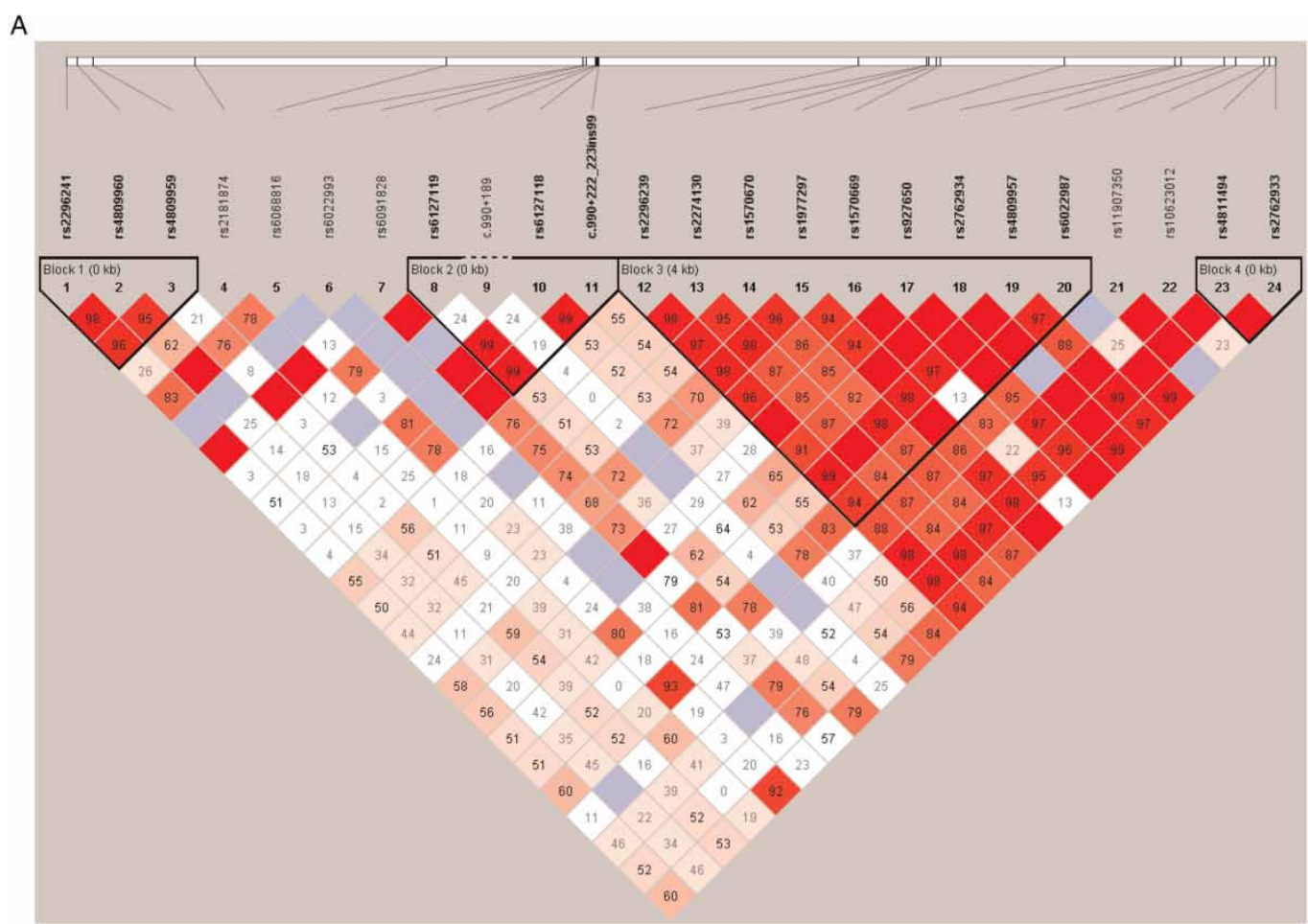

B

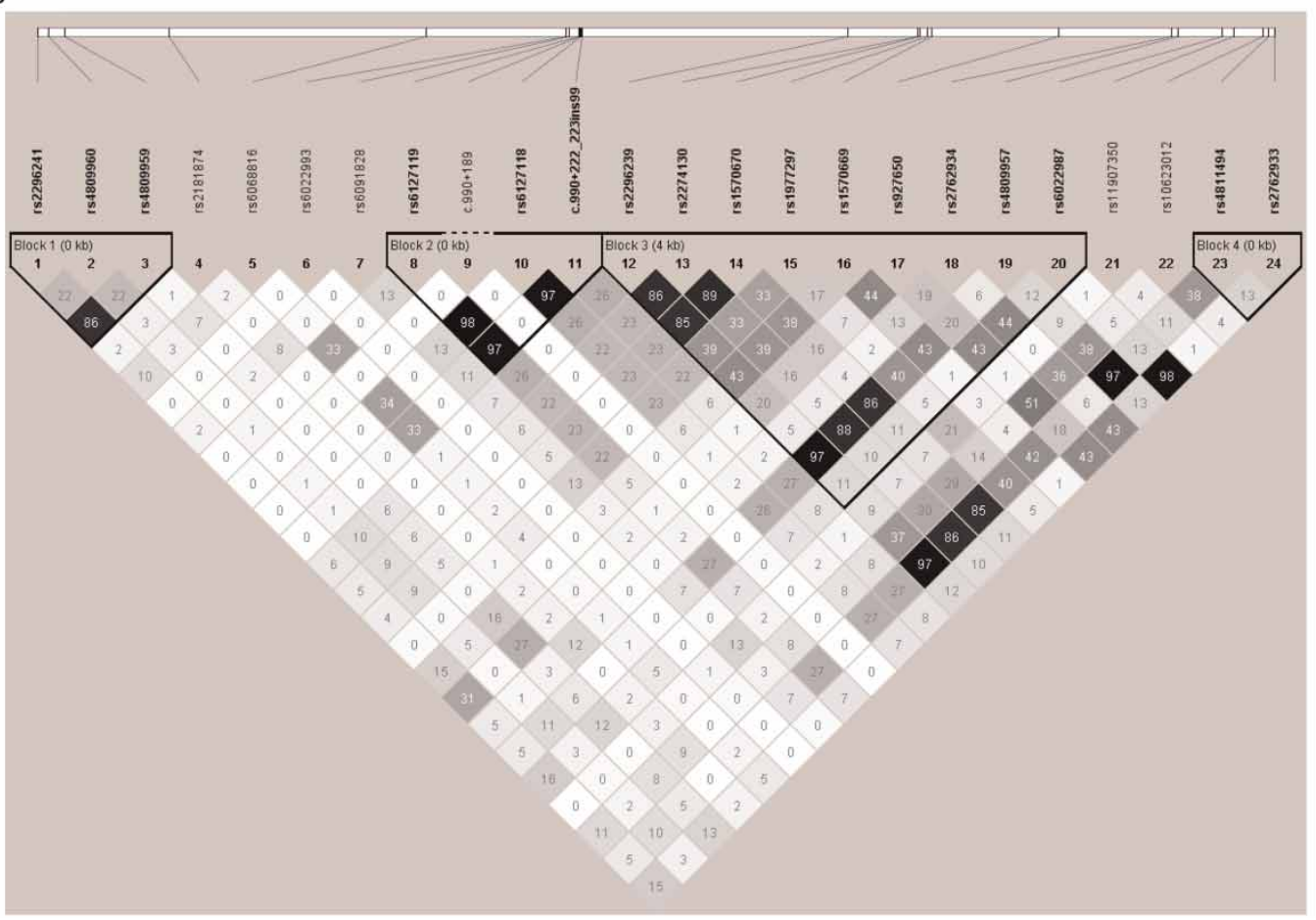

Figure 5. Linkage disequilibrium in the extended sibpair cohort. (A) shows linkage disequilibrium measures in $D^{\prime}$ and (B) shows linkage disequilibrium measures in $r^{2}$ 
Table 4. Single SNP association results comparing all AMD subtypes with normal subjects

\begin{tabular}{|c|c|c|c|c|c|c|c|c|c|c|}
\hline \multirow[b]{2}{*}{ SNP } & \multirow[b]{2}{*}{ Gene } & \multirow[b]{2}{*}{ Allele } & \multicolumn{2}{|c|}{ Expanded sibpair cohort } & \multicolumn{2}{|l|}{ Greeks } & \multicolumn{2}{|c|}{ NHS/HPFS } & \multicolumn{2}{|c|}{ Meta-analysis } \\
\hline & & & $\begin{array}{l}\text { Odds ratio } \\
(95 \% \mathrm{Cl})\end{array}$ & $p$-Value & $\begin{array}{l}\text { Odds ratio } \\
(95 \% \mathrm{Cl})\end{array}$ & p-Value & $\begin{array}{l}\text { Odds ratio } \\
(95 \% \mathrm{CI})\end{array}$ & $p$-Value & $\begin{array}{l}\text { Odds ratio } \\
\text { (95\% Cl) }\end{array}$ & p-Value \\
\hline rs2189480 & VDR & A & $1.801(1.069-3.035)$ & 0.0270 & $1.199(0.846-1.700)$ & 0.3080 & $0.903(0.766-1.064)$ & 0.2213 & $0.997(0.865-1.15 \mid)$ & 0.9710 \\
\hline rs229624I & CYP24AI & C & $1.345(0.829-2.182)$ & 0.2294 & $1.185(0.842-1.668)$ & 0.3306 & & & $1.036(0.814-1.319)$ & $0.77 I I$ \\
\hline rs4809960 & CYP24AI & G & $0.983(0.567-1.703)$ & 0.9515 & $1.027(0.690-1.527)$ & 0.8967 & & & I.I I $6(0.843-1.477)$ & 0.4425 \\
\hline rs4809959 & CYP24AI & $\mathrm{T}$ & $1.238(0.770-1.989)$ & 0.3781 & $1.058(0.76|-| .470)$ & 0.7369 & & & I. $124(0.885-1.427)$ & 0.3391 \\
\hline rs2181874 & CYP24AI & $\mathrm{T}$ & $0.87 \mid(0.50|-| .5 \mid 5)$ & 0.6242 & $0.687(0.48 I-0.983)$ & 0.0400 & $0.989(0.812-1.204)$ & 0.9116 & $0.894(0.763-1.046)$ & 0.1629 \\
\hline rs60688I6 & CYP24AI & $A$ & $2.081(0.945-4.586)$ & 0.0690 & I.14I (0.695-I.875) & 0.6012 & & & $1.243(0.85|-| .8 \mid 7)$ & 0.2600 \\
\hline rs6091828 & CYP24AI & A & I.338 (0.28I-6.382) & $0.7 \mid 48$ & $0.536(0.206-1.393)$ & 0.2006 & & & $0.745(0.356-1.560)$ & 0.4352 \\
\hline rs6127I19 & CYP24AI & $A$ & $1.284(0.724-2.274)$ & 0.3924 & $1.245(0.83 \mid-1.865)$ & 0.2881 & & & $1.257(0.937-1.688)$ & 0.1275 \\
\hline $\begin{array}{l}c .990+189 \\
G>A\end{array}$ & CYP24AI & A & $0.887(0.138-5.700)$ & 0.8993 & $1.699(0.323-8.925)$ & 0.5312 & & & I.I23 (0.347-3.630) & 0.8464 \\
\hline rs6127II8 & CYP24AI & $\mathrm{T}$ & $1.297(0.725-2.319)$ & 0.3816 & $1.274(0.845-1.921)$ & $0.247 I$ & $1.050(0.864-1.276)$ & 0.6230 & I.III (0.946-I.305) & 0.1995 \\
\hline $\begin{array}{l}\text { c. } 990+222- \\
223 \text { ins } 99\end{array}$ & CYP24AI & ins & I.34I (0.744-2.4I7) & 0.3288 & $1.297(0.867-1.939)$ & 0.2055 & $1.086(0.874-1.350)$ & 0.4564 & I.I $45(0.963-1.363)$ & 0.1258 \\
\hline rs2296239 & CYP24AI & $A$ & $1.457(0.819-2.590)$ & 0.2000 & $1.529(0.976-2.396)$ & 0.0638 & $1.205(0.993-1.463)$ & 0.0584 & $1.217(1.035-1.430)$ & 0.0174 \\
\hline rs2274I30 & CYP24AI & C & I.75I (0.975-3.I47) & 0.0610 & $1.512(0.970-2.358)$ & 0.0679 & $1.255(1.029-1.529)$ & 0.0247 & $1.248(1.059-1.47)$ & 0.0082 \\
\hline rs 1570670 & CYP24AI & C & I.790 (0.98I-3.267) & 0.0579 & $1.512(0.970-2.358)$ & 0.0679 & I.195 (0.984-1.452) & 0.0725 & $1.220(1.037-1.436)$ & 0.0165 \\
\hline rs 1977297 & CYP24AI & A & $0.725(0.293-|.79|)$ & 0.4856 & I. $142(0.62 I-2.101)$ & 0.6693 & & & $1.009(0.643-1.582)$ & 0.9694 \\
\hline rs 1570669 & CYP24AI & C & I.I53 (0.690-1.927) & 0.5875 & $1.287(0.894-1.852)$ & 0.1753 & $1.309(1.104-1.55 \mathrm{I})$ & 0.0019 & $1.285(1.116-1.478)$ & 0.0005 \\
\hline rs927650 & CYP24AI & A & $0.914(0.596-1.402)$ & 0.6804 & $1.468(1.048-2.056)$ & 0.0257 & $0.853(0.728-0.999)$ & 0.0487 & $0.969(0.852-1.102)$ & 0.6316 \\
\hline rs2762934 & CYP24AI & $\mathrm{T}$ & $0.743(0.367-1.502)$ & 0.4082 & $1.067(0.704-1.619)$ & 0.7595 & $0.930(0.754-1.148)$ & 0.5016 & $0.949(0.798-1.130)$ & 0.5574 \\
\hline rs4809957 & CYP24AI & C & $1.475(0.822-2.644)$ & 0.1925 & $1.462(0.943-2.268)$ & 0.0896 & I.19I (0.98I-I.445) & 0.0772 & $1.196(1.017-1.405)$ & 0.0300 \\
\hline rs6022987 & CYP24AI & G & $0.755(0.427-1.336)$ & 0.3347 & $1.169(0.804-1.699)$ & 0.4136 & & & I. $109(0.845-1.456)$ & 0.4567 \\
\hline rs|l907350 & CYP24AI & $\mathrm{T}$ & $0.363(0.066-2.000)$ & 0.2445 & $1.296(0.438-3.836)$ & 0.6397 & $1.246(0.829-1.872)$ & 0.2896 & I.III (0.772-I.598) & 0.5711 \\
\hline
\end{tabular}


$(p=0.02)$. This was the SNP that the minor allele was defined as (A) and the Sibling cohort and the NHS/HPFUS, but was defined as $(G)$ in the Greeks. Overall, the test for heterogeneity was not statistically significant $(p>0.1)$.

\section{Bioinformatic analysis of potential function of variants}

Of the SNPs found to be significantly associated with AMD, three SNPs were well conserved across species: rs2296239, rs2274130 and rs1570670, spanning from exon 8 to intron 9 of CYP24A1. Transcription Element Search System (TESS) analysis showed that, of our five significant SNPs, three SNPs changed or created transcription factor binding sites with the presence of the minor allele. Specifically, the minor allele of rs2274130 eliminated the binding site of B factor T00286 factor i T00557 NF-E2; rs1570670 changed the binding site from Gata-1 to GR; and the minor allele of rs1570669 changed the binding site from NF-BA1 to STE12. Using the publicly available eQTL database mRNA by SNP Browser $\mathrm{v}$ 1.0.1, ${ }^{5,57}$ we investigated the association of the CYP24A1 SNPs that were significant alone or as part of a haplotype with eQTLs. Of our six SNPs, rs2181874 and rs1570669 were associated with the genes TSC22 domain family, member 1 (TSC22D1), unc-51-like kinase 2 (ULK2) and ring finger protein 213 (RNF213), respectively. These results suggest that further experimental analysis of these data would be worthwhile.

In order to identify causal variation, the creation of putative splice sites by genetic variants was analysed by inputting sequence into the alternative splice site predictor (http://www.es.embnet.org/ mwang/assp. html) (using the default parameters). Splice site analysis of the minor allele $(G)$ of rs927650 - the SNP most significantly associated with an increased risk of AMD in the Greek cohort-predicted the creation of an alternative isoform/cryptic donor at the bp immediately preceding this SNP (chromosome 20: 52772742) within intron 11 of the longest CYP24A1 transcript (CYP24A1-003) with a score of 10.967. Further studies should be conducted to test this prediction in a biological setting.

\section{Pathway analyses}

IPA analyses indicated that five genes ( $R X R A, V D R$, PTH, CYP24 and CYP24A1) involved in the regulation of vitamin $\mathrm{D}$ metabolism, are connected by direct and indirect relationships to one AMD-associated gene (HTRA1) for which the pathway is unknown. ${ }^{10,38,52,60-62}$ Additionally, some of these pathway genes directly or indirectly interact with genes involved in angiogenesis (the CALR, catenin [cadherin-associated protein] beta 1 (CTNNB1), bone morphogenetic protein 4 (BMP4) and interleukin 6 [ILG] genes), one of the hallmarks of neovascular AMD.

As the pathway map shows (Figure 6), some of the genes are implicated in both AMD and vitamin D pathways (VDR and CYP24A1), or both angiogenesis and AMD (BMP4). When the pathways linking the genes/proteins described above are grown to incorporate other related molecules, the retinoid $\mathrm{X}$ receptor- $\alpha$ gene $(R X R A)$, encoding a ligand-dependent nuclear receptor which binds directly to VDR, is identified as a potentially relevant gene in the pathogenesis of AMD, given its role in the inflammatory response. Clearly, the genes illustrated in our pathway map are involved in multiple processes. Although it is a hypothetical pathway, the map may help to explain the protective anti-inflammatory and anti-angiogenic role of vitamin $\mathrm{D}$ in the likelihood of developing AMD.

\section{Analysis of interactions between gene variants and environmental factors}

For gene-gene interactions, all CYP24A1 SNPs were tested for interaction with well-established risk genotypes in $A R M S 2 / H T R A 1, C F H$ and $R O R A$ for which we had previous genotyping data and, furthermore, for interaction with $V D R$ rs2189480. Analysis of all AMD subtypes compared with unaffected individuals showed several CYP24A1 SNPs and VDR rs2189480 to interact modestly, but these associations did not remain significant after adjusting for multiple comparisons. The pooled case-only analysis showed no significant interactions between CYP24A1 SNPs and VDR rs2189480. 

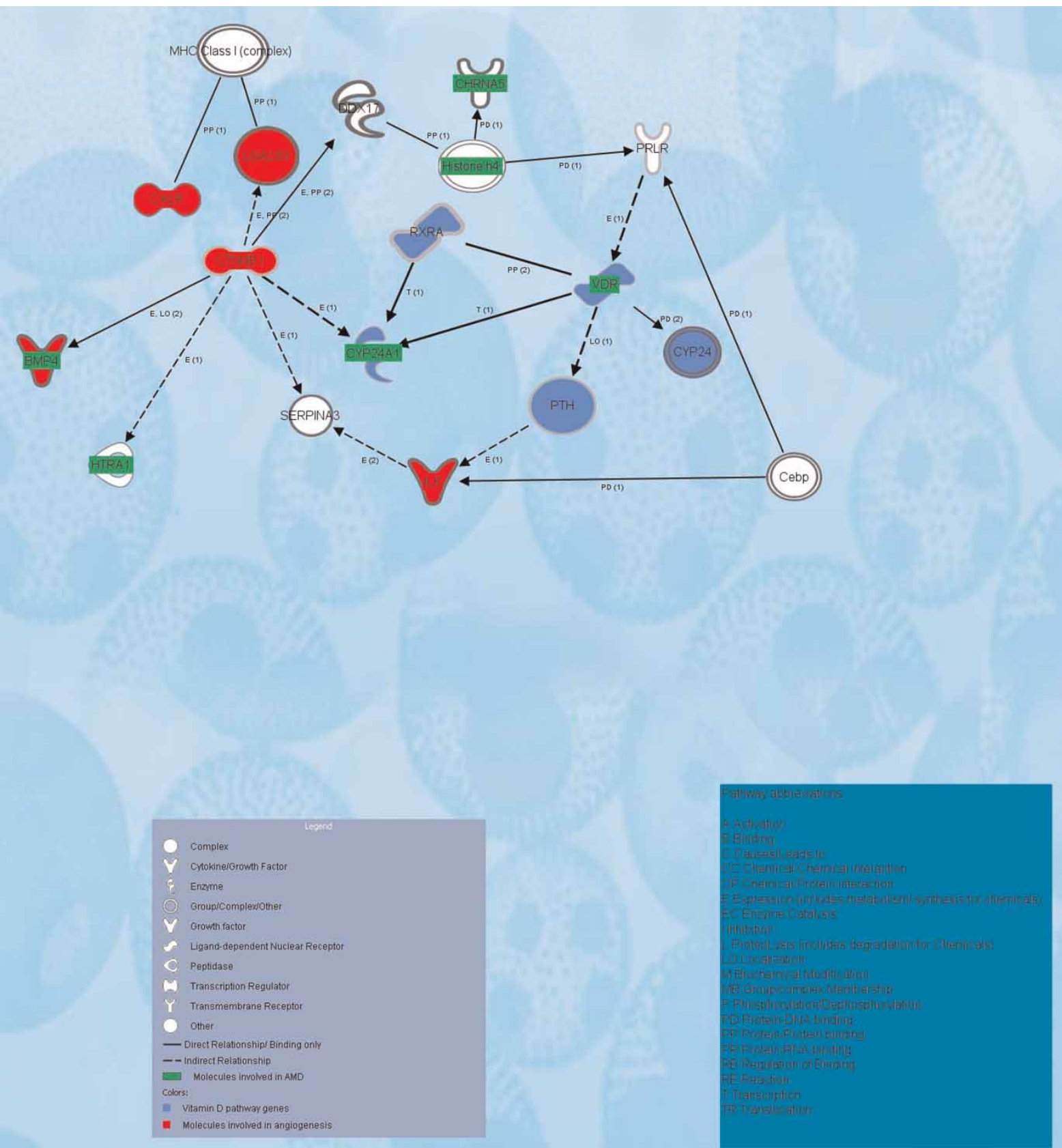

Figure 6. IPA pathway analysis of vitamin D metabolism. Graphical representation of the relationships between genes/proteins (represented as nodes). The biological relationship between two nodes is represented as a line (segmented to illustrate indirect relationships and continuous to illustrate direct relationships). All lines are supported by at least one reference from the literature or from canonical information stored in the Ingenuity Pathways Knowledge Base. Nodes are displayed using various shapes to illustrate the functional class of the gene product.

Interaction between both CYP24A1 and $V D R$ variants and sunlight exposure was also tested using CLR in SAS. No significant interaction was found between UV irradiation and any of the variants tested (data not shown).

\section{Discussion}

Many pathways and processes involved in the progression of systemic disorders such as cancer, cardiovascular disease and autoimmune diseases are also 
thought to be involved in AMD. It is therefore likely that valuable insights into the pathophysiology of AMD may be gained by studying pathways common to AMD and other well-characterised diseases that may overlap in pathogenesis. In fact, cross-talk between disease fields has already proven beneficial for the treatment of AMD: anti-vascular endothelial growth factor (anti-VEGF) antibodies initially developed for the treatment of cancer are currently the most effective treatment for neovascular AMD. ${ }^{3}$

The important role of vitamin $\mathrm{D}$ in diseases of complex aetiology, its anti-angiogenic properties and an association between vitamin D serum levels and early AMD led us initially to explore the association between vitamin $\mathrm{D}$ and neovascular AMD by examining vitamin $\mathrm{D}$-associated epidemiological factors and genetic variants of vitamin $\mathrm{D}$ metabolism genes in an extremely discordant sibling pair cohort. Here, we showed a protective effect of UV exposure on the development of neovascular AMD. Further, we identified several CYP24A1 SNPs significantly associated with all subtypes of AMD in four diverse cohorts, both retrospectively and prospectively. Moreover, these significant associations were demonstrated in a meta-analysis of the four cohorts. To the best of our knowledge, this was the first study to demonstrate a protective effective of UV exposure on the development of AMD and a genetic link between vitamin $\mathrm{D}$ metabolism and AMD.

The role of sunlight in AMD pathophysiology remains controversial. Human exposure to natural sunlight may be both beneficial and detrimental. One benefit of cutaneous sunlight exposure is the production of vitamin D. Studies have also shown that vitamin D produced as a result of sunlight exposure reduces the risk of autoimmune diseases such as multiple sclerosis (MS) and inflammatory bowel disease (IBD). ${ }^{63}$ By contrast, natural sunlight (ie UV exposure) has long been known to have harmful effects on the human body, including permanent DNA damage. For example, studies have linked sunlight exposure to skin cancer, for both melanomas ${ }^{64,65}$ and carcinomas. ${ }^{66}$ In dermatological malignancies, the most detrimental factor is UVB, but UVA may also play a role.
To distinguish between the effects of general sunlight exposure and specifically UV exposure, sunlight exposure was self-assessed by patients and UV exposure was quantified separately by examining UV radiation, as measured in irradiance of UVB $(290 \mathrm{~nm}$ to $320 \mathrm{~nm})$, UVA $(320 \mathrm{~nm}$ to $400 \mathrm{~nm}$ ) and UV index. In addition, we examined vitamin supplementation, as well as sun-related variables including iris colour, self-reported sun exposure and skin cancer history. We also measured $25(\mathrm{OH}) \mathrm{D}$ in sera as a biomarker for vitamin $\mathrm{D}$ levels. To the best of the authors' knowledge, this was the first examination of sunlight exposure in the context of established AMD risk genotypes and smoking.

Quantification of sunlight exposure is difficult, as it is an ongoing life-long process. ${ }^{67-79}$ One of the first studies of ocular exposure to UV based on interview data and field measurements in Chesapeake Bay watermen demonstrated no association between UV exposure and AMD. ${ }^{79}$ Further analysis of this same dataset showed that there was in fact an association between AMD and ocular exposure, but to blue light specifically. ${ }^{76,78}$ Alternatively, various studies have tested the association of sunlight exposure and AMD by measuring various sun-related variables. For example, Khan et al. investigated the role of variables such as iris colour, place of residence and hair colour but found no association between AMD and these sun related factors. ${ }^{80}$ Cruickshanks et al. measured lifetime number of sunburns, use of hats and sunglasses and number of hours spent outdoors, and showed an association between leisure time spent outdoors and risk of early AMD. ${ }^{69}$ Our study demonstrated a protective effect of moderate levels of UV radiation exposure and AMD, independent of smoking history and CFH and HTRA1 genotype. While experimental studies have shown that UV light has damaging effects on the retina-primarily via oxidative damage and formation of reactive oxygen species $^{81}$ - previous epidemiological studies have shown inconsistent results regarding an association between UV light and risk of AMD. ${ }^{67-79}$ UV light is part of the sunlight spectrum, but only UVA $(320-400 \mathrm{~nm})$ and UVB $(280-320 \mathrm{~nm})$ reach the 
Earth's surface. UV light has traditionally been considered harmful because it induces DNA damage and causes oxidative damage to RPE cells. ${ }^{82-84}$ Furthermore, UV light has been shown to have pro-angiogenic properties. UVA-irradiated RPE cells have been shown to have increased levels of prostaglandin-endoperoxide synthase 2 (also known as cyclooxygenase-2 [COX2]), ${ }^{85}$ which is implicated in choroidal neovascularisation. ${ }^{86}$ UVB-induced tumours express elevated levels of factors associated with angiogenesis, including VEGF, matrix metallopeptidase 2 (MMP2) and matrix metallopeptidase 3 (MMP3). ${ }^{87}$

Emerging evidence shows that solar radiation may have beneficial effects, however. Epidemiological studies have demonstrated that sunlight reduces the incidence and mortality of various cancers, including non-Hodgkin's lymphoma and melanoma. ${ }^{88,89} \mathrm{UV}$ light is known to suppress the immune response ${ }^{90}$ and growing evidence points to the role of inflammation in AMD pathogenesis. Since aberrant inflammation is believed to be a contributing factor to AMD, the immunosuppressive effects of UV radiation may provide some protective effect.

We specifically examined the role of UV light and AMD in this study, although previous studies have mainly looked at ambient sunlight exposure. Previous studies have been inconsistent about the role of sunlight exposure and AMD. ${ }^{67-79,91,92}$ Some studies suggested a positive association, ${ }^{69,76,91,92}$ while others found no correlation. ${ }^{71,78,93}$ To our knowledge, our study was the first to show a protective influence of UV light on neovascular AMD. Our finding may contrast with previous studies as a result of using a larger number of neovascular cases $(n=133)$ than that used in most previous studies. Furthermore, previous studies measured ambient solar radiation, which includes light of various wavelengths (UV, infrared, visible), while our study distinguished the contribution of UV irradiance.

Although our gene expression studies on vitamin D metabolism genes in human donor eyes found no significant association as a function of age or disease status, differences in expression levels between the macular and extramacular regions were observed. Specifically, the expression of both VDR and $C Y P 27 A 1$ was detected in the RPE-choroid, and CYP27A1 and CYP27B1 were detected in the retina, thus suggesting that the vitamin $D$ metabolic genes VDR and CYP27B1 may function differently between the maculae and extramaculae, whether diseased or non-diseased. Also, AMD may not be a localised disease but rather may manifest systemically, and this may explain why CYP24A1 was not detected in human retinal tissue regardless of disease status. The gene expression changes that we observed in retinal cell lines suggested that CYP24A1 activity may alter over time and this would support its role in a late-onset disease such as AMD.

There were several limitations to this study. First, there was the possibility of recall bias. There was no definitive method to confirm an individual's recall of personal sun exposure and thus data could have been prone to misclassification. We attempted to minimise this bias by using a quantitative measurement of UV exposure based on the geographical location where the participants had resided for the majority of their lifetime; however, assessment of UV radiation based on residential history represents potential rather than actual exposure and could be subject to error. Secondly, although the subjects were questioned about the amount of time they spent outdoors, no information was gathered about their use of protection against sunlight, such as hats and sunglasses, which shield against UV light. Further, the subjects' sera were collected at various times throughout the year, and thus serum levels of vitamin D measured in this study may not accurately have represented the true range among the patient population, since vitamin D levels are influenced by sunlight exposure, diet and age.

Although a previous study by Parekh et al. showed an inverse relationship between vitamin D levels and early AMD but not late $\mathrm{AMD}^{34}$ this study was limited by a small number of patients with an advanced form of AMD $(n=10)$. A more recent study by Millen et al. was able to show a statistically significant association between serum $25(\mathrm{OH}) \mathrm{D}$ concentrations and early AMD in women younger than 75 years; specifically, that 
high serum $25(\mathrm{OH}) \mathrm{D}$ concentrations may be protective. ${ }^{94}$ In our study, we further investigated the association of serum levels of $25(\mathrm{OH}) \mathrm{D}$, the circulating form of vitamin $\mathrm{D}$, with neovascular AMD by analysing the serum levels of 50 extremely discordant sibling pairs $(n=100)$. Our results were similar to those found by Millen and colleagues: a trend towards higher levels of vitamin D in the serum of unaffected patients compared with neovascular patients, although the difference was not statistically significant. Since the ability to produce vitamin $\mathrm{D}$ is diminished with advanced age (ageing results in decreased amounts of cutaneous 7-dehydrocholesterol, and by 70 years of age vitamin $\mathrm{D}_{3}$ synthesis is reduced by approximately 75 per cent ${ }^{95}$ ), it is not unexpected that serum vitamin $\mathrm{D}$ levels were low, given that the average age of our unaffected patients was 75.4 years. This could explain why the association was not significant. Additionally, since this was measured only once, the serum values reflected the vitamin D production/intake over a limited amount of time, thus suggesting enhanced random measurement error.

In addition to epidemiological data, the association of AMD with genetic variation in vitamin D pathway genes was further suggested by existing linkage data for genomic regions associated with AMD. The vitamin D pathway genes assayed in this study all lie within regions that have been associated with AMD - specifically, 2q33 ${ }^{48}$ (CYP27A1), $12 \mathrm{q} 13^{36}(C Y P 27 B 1$ and $V D R)$, and $20 \mathrm{q} 13^{36}$ (CYP24A1).

The CYP24A1 SNPs significantly associated with neovascular AMD in the discovery cohort (either individually [rs6127118 and rs2769234] or as part of a haplotype [rs6068816, rs6127118, rs1570699, rs92760 and rs2762934]) were concentrated in the area between exon 6 and exon 12 . This area was further examined and refined by direct sequencing and analysed in an extended sibling cohort. After controlling for smoking history, sex and age, we were able to show significant variation in CYP24A1 in all populations, both separately and, more importantly, in a meta-analysis. Variation within CYP24A1 was available in the dbGAP dataset (http://www.ncbi.nlm.nih.gov/ projects/gap/) but, when tested for association with AMD, no significance was observed. This lack of association could be explained by the small number of subjects in the dbGAP dataset, as compared with the current study ( $n=500$ and 2,528, respectively). Additionally, these data were based on a 100,000 SNP chip, and the CYP24A1 variation was imputed with low imputation quality, which is another limitation of the dbGAP dataset.

Moreover, pathway analysis showed that, in a hypothetical pathway, CYP24A1 was directly linked to another AMD-associated gene, HTRA1, for which the exact pathway is unknown. In a complex disease such as AMD, one would expect the combination of multiple effects, including the modest effect of CYP24A1, to contribute to disease causality. Although there was no statistical interaction seen between CYP24A1 and HTRA1, there may have been binding between the two that differed between those with and those without AMD. Further molecular studies should be performed to investigate this association.

An anti-angiogenic role for vitamin $\mathrm{D}$ has been well documented in the cancer literature. ${ }^{96-98}$ Therefore, a role for vitamin $\mathrm{D}$ may be protective of AMD by its anti-angiogenic properties. ${ }^{27}$ For example, VEGF expression was downregulated after tumour cells were treated with vitamin $\mathrm{D}^{25,26}$ Vitamin D may exert anti-inflammatory properties by enhancing $\mathrm{T}$ suppressor cell activity and downregulating $\mathrm{T}$ helper cells, $\mathrm{T}$ cytotoxic cells and natural killer cells. ${ }^{28}$ At physiological concentrations, vitamin $\mathrm{D}$ has also been shown to protect cell proteins and membranes from oxidative damage. ${ }^{30}$ In addition to playing a role in cancer, the vitamin D pathway has been implicated in several autoimmune diseases. Several studies have found that low levels of vitamin D are associated with increased autoimmunity.

A role for vitamin $\mathrm{D}$ in AMD is not only plausible in terms of the known biological roles of vitamin $\mathrm{D}$, but also because of the diminished ability to produce vitamin $\mathrm{D}$ with advanced age. ${ }^{99}$ The problem of vitamin D deficiency is not only prevalent among the elderly: as of 2005, approximately 40 per cent of men and 50 per cent of 
women aged over 18 from the USA were estimated to have inadequate levels of $25(\mathrm{OH}) \mathrm{D} .{ }^{100}$

\section{Conclusion}

In summary, using multiple lines of evidence, this study demonstrated an association between the vitamin D pathway and AMD. Specifically, there is a protective association between UV radiation and neovascular AMD which is independent of smoking and CFH and HTRA1 polymorphisms. Additionally, we identified an association between genetic variation in the major vitamin $\mathrm{D}$ catabolic gene, CYP24A1, and risk for all forms of AMD and, specifically, the neovascular form of AMD. Further experiments are needed to elucidate the role of vitamin D and UV light in the pathogenesis of AMD. Ongoing large-scale trials of supplemental vitamin $\mathrm{D}$ may provide a unique opportunity to examine the effects of vitamin D on AMD in a randomised trial setting. Such studies may have important implications for the prevention and/or treatment of neovascular AMD by the regulation of modifiable lifestyle factors that influence levels of vitamin D.

\section{Acknowledgments}

We thank the patients and their siblings for their participation in this study. We also thank Anne Marie Lane, Amanda Harring and Trevor Arneberg for their help on this project and Fei Ji, for critical and helpful discussions on statistical analysis.

This work was supported by grants from the Lincy Foundation; the Massachusetts Lions; Friends of the Massachusetts Eye and Ear Infirmary; Genetics of Age-related Macular Degeneration Fund; MEEI; the Edward N. \& Della L. Thome Memorial Foundation; an unrestricted grant from Research to Prevent Blindness, Inc. to the Department of Ophthalmology and Visual Sciences, University of Utah; Hope for Vision and the National Institutes of Health [EY014458, EY14104, EY017362, EY017404].

\section{References}

1. Hanahan, D. and Weinberg, R.A. (2000), 'The hallmarks of cancer', Cell Vol. 100, pp. 57-70.

2. Ding, X., Patel, M. and Chan, C.-C. (2009), 'Molecular pathology of age-related macular degeneration', Prog. Retin. Eye Res. Vol. 28, pp. $1-18$.
3. Jager, R.D., Mieler, W.F. and Miller, J.W. (2008), 'Age-related macular degeneration', N. Engl. J. Med. Vol. 358, pp. 2606-2617.

4. Anderson, D.H., Mullins, R.F., Hageman, G.S. and Johnson, L.V. (2002), 'A role for local inflammation in the formation of drusen in the aging eye', Am. J. Ophthalmol. Vol. 134, pp. 411-431.

5. Hageman, G.S., Luthert, P.J., Victor Chong, N.H, Johnson, L.V. et al. (2001), 'An integrated hypothesis that considers drusen as biomarkers of immune-mediated processes at the RPE-Bruch's membrane interface in aging and age-related macular degeneration', Prog. Retin. Eye Res. Vol. 20, pp. 705-732.

6. Beatty, S., Koh, H., Phil, M., Henson, D. et al. (2000), 'The role of oxidative stress in the pathogenesis of age-related macular degeneration', Surv. Ophthalmol. Vol. 45, pp. 115-134.

7. Dong, A., Xie, B., Shen, J., Yoshida, T. et al. (2009), 'Oxidative stress promotes ocular neovascularization', J. Cell. Physiol. Vol. 219, pp. 544-552.

8. Dong, L.M., Ulrich, C.M., Hsu, L., Duggan, D.J. et al. (2009), 'Vitamin D related genes, CYP24A1 and CYP27B1, and colon cancer risk', Cancer Epidemiol. Biomarkers Prev. Vol. 18, pp. 2540-2548.

9. Haines, J.L., Hauser, M.A., Schmidt, S., Scott, W.K. et al. (2005), 'Complement factor $\mathrm{H}$ variant increases the risk of age-related macular degeneration', Science Vol. 308, pp. 419-421.

10. Jakobsdottir, J., Conley, Y.P., Weeks, D.E., Mah, T.S. et al. (2005), 'Susceptibility genes for age-related maculopathy on chromosome 10q26', Am. J. Hum. Genet. Vol. 77, pp. 389-407.

11. Khansari, N., Shakiba, Y. and Mahmoudi, M. (2009), 'Chronic inflammation and oxidative stress as a major cause of age-related diseases and cancer', Recent Pat. Inflamm. Allergy Drug Discov. Vol. 3, pp. 73-80.

12. Klein, R., Klein, B.E.K., Knudtson, M.D., Wong, T.Y. et al. (2005), 'Systemic markers of inflammation, endothelial dysfunction, and age-related maculopathy', Am. J. Ophthalmol. Vol. 140, pp. 35-44.

13. Murdoch, C., Muthana, M., Coffelt, S.B. and Lewis, C.E. (2008), 'The role of myeloid cells in the promotion of tumour angiogenesis', Nat. Rev. Cancer Vol. 8, pp. 618-631.

14. Ostrand-Rosenberg, S. and Sinha, P. (2009), 'Myeloid-derived suppressor cells: Linking inflammation and cancer', J. Immunol. Vol. 182, pp. 4499-4506.

15. Pan, J.-S., Hong, M.-Z. and Ren, J.-L. (2009), 'Reactive oxygen species: A double-edged sword in oncogenesis', World J. Gastroenterol. Vol. 15, pp. 1702-1707.

16. Pittet, M.J. (2009), 'Behavior of immune players in the tumor microenvironment', Curr. Opin. Oncol. Vol. 21, pp. 53-59.

17. Shan, W., Yang, G. and Liu, J. (2009), 'The inflammatory network: Bridging senescent stroma and epithelial tumorigenesis', Front. Biosci. Vol. 14, pp. 4044-4057.

18. Swaroop, A., Chew, E.Y., Rickman, C.B. and Abecasis, G.R. (2009), 'Unraveling a multifactorial late-onset disease: From genetic susceptibility to disease mechanisms for age-related macular degeneration', Annu. Rev. Genomics Hum. Genet. Vol. 10, pp. 19-43.

19. Visconti, R. and Grieco, D. (2009), 'New insights on oxidative stress in cancer', Curr. Opin. Drug Discov. Devel. Vol. 12, pp. 240-245.

20. Deeb, K.K., Trump, D.L. and Johnson, C.S. (2007), 'Vitamin D signalling pathways in cancer: Potential for anticancer therapeutics', Nat. Rev. Cancer Vol. 7, pp. 684-700.

21. Egan, K.M. (2009), 'Vitamin D and melanoma', Ann. Epidemiol. Vol. 19, pp. $455-461$.

22. Garland, F.C., Garland, C.F., Gorham, E.D. and Young, J.F. (1990), 'Geographic variation in breast cancer mortality in the United States: A hypothesis involving exposure to solar radiation', Prev. Med. Vol. 19, pp. 614-622.

23. Lefkowitz, E.S. and Garland, C.F. (1994), 'Sunlight, vitamin D, and ovarian cancer mortality rates in US women', Int. J. Epidemiol. Vol. 23, pp. 1133-1136.

24. Holick, M.F. (1996), 'Vitamin D and bone health', J. Nutr. Vol. 126 (4 Suppl.), pp. 1159S-1164S.

25. Shokravi, M.T., Marcus, D.M., Alroy, J., Egan, K. et al. (1995), 'Vitamin D inhibits angiogenesis in transgenic murine retinoblastoma', Invest. Ophthalmol. Vis. Sci. Vol. 36, pp. 83-87. 
26. Iseki, K., Tatsuta, M., Uehara, H., Iishi, H. et al. (1999), 'Inhibition of angiogenesis as a mechanism for inhibition by 1alpha-hydroxyvitamin D3 and 1,25-dihydroxyvitamin D3 of colon carcinogenesis induced by azoxymethane in Wistar rats', Int. J. Cancer Vol. 81, pp. 730-733.

27. Hansen, C.M., Hansen, D., Holm, P.K. and Binderup, L. (2001), 'Vitamin D compounds exert anti-apoptotic effects in human osteosarcoma cells in vitro', J. Steroid Biochem. Mol. Biol. Vol. 77, pp. 1-11.

28. Hayes, C.E., Nashold, F.E., Spach, K.M. and Pedersen, L.B. (2003), 'The immunological functions of the vitamin D endocrine system', Cell. Mol. Biol. (Noisy-le-grand), Vol. 49, pp. 277-300.

29. Abe, E., Miyaura, C., Sakagami, H., Takeda, M. et al. (1981), 'Differentiation of mouse myeloid leukemia cells induced by 1 alpha,25dihydroxyvitamin D3', Proc. Natl. Acad. Sci. USA Vol. 78, pp. 4990-4994.

30. Ravid, A. and Koren, R. (2003), 'The role of reactive oxygen species in the anticancer activity of vitamin D', Recent Results Cancer Res. Vol. 164, pp. 357-367.

31. Ahn, J., Albanes, D., Berndt, S.I., Peters, U. et al. (2009), 'Vitamin D-related genes, serum vitamin D concentrations and prostate cancer risk', Carcinogenesis Vol. 30, pp. 769-776.

32. Bär, M., Domaschke, D., Meye, A., Lehmann, B. et al. (2007), 'Wavelength-dependent induction of CYP24A1-mRNA after UVB-triggered calcitriol synthesis in cultured human keratinocytes', J. Invest. Dermatol. Vol. 127, pp. 206-213.

33. Lanske, B. and Razzaque, M.S. (2007), 'Vitamin D and aging: Old concepts and new insights', J. Nutr. Biochem. Vol. 18, pp. 771-777.

34. Parekh, N., Chappell, R.J., Millen, A.E., Albert, D.M. et al. (1994), 'Association between vitamin D and age-related macular degeneration in the Third National Health and Nutrition Examination Survey, 1988 through 1994', Arch. Ophthalmol. Vol. 125, pp. 661-669.

35. Seddon, J.M., Santangelo, S.L., Book, K., Chong, S. et al. (2003), 'A genomewide scan for age-related macular degeneration provides evidence for linkage to several chromosomal regions', Am. J. Hum. Genet. Vol. 73, pp. 780-790.

36. Iyengar, S.K., Song, D., Klein, B.E.K., Klein, R. et al. (2004), 'Dissection of genomewide-scan data in extended families reveals a major locus and oligogenic susceptibility for age-related macular degeneration', Am. J. Hum. Genet. Vol. 74, pp. 20-39.

37. DeAngelis, M.M., Lane, A.M., Shah, C.P., Ott, J. et al. (2004), 'Extremely discordant sib-pair study design to determine risk factors for neovascular age-related macular degeneration', Arch. Ophthalmol. Vol. 122 , pp. $575-580$.

38. DeAngelis, M.M., Ji, F., Adams, S., Morrison, M.A. et al. (2008), 'Alleles in the HtrA serine peptidase 1 gene alter the risk of neovascular age-related macular degeneration', Ophthalmology Vol. 115, pp. 1209-1215.e7.

39. Age-Related Eye Disease Study Research Group (2001), 'A randomized, placebo-controlled, clinical trial of high-dose supplementation with vitamins $\mathrm{C}$ and $\mathrm{E}$, beta carotene, and zinc for age-related macular degeneration and vision loss: AREDS report no. 8', Arch. Ophthalmol. Vol. 119, pp. 1417-1436.

40. Silveira, A.C., Morrison, M.A., Ji, F, Xu, H. et al. (2010), 'Convergence of linkage, gene expression and association data demonstrates the influence of the RAR-related orphan receptor alpha (RORA) gene on neovascular AMD: A systems biology based approach', Vision Res. Vol. 50, pp. 698-715.

41. Klein, R., Klein, B.E.K., Tomany, S.C. and Moss, S.E. (2002), 'Ten-year incidence of age-related maculopathy and smoking and drinking: The Beaver Dam Eye Study', Am. J. Epidemiol. Vol. 156, pp. 589-598.

42. Schaumberg, D.A., Chasman, D., Morrison, M.A., Adams, S.M. et al. (2010), 'Prospective study of common variants in the retinoic acid receptor-related orphan receptor $\alpha$ gene and risk of neovascular age-related macular degeneration', Arch. Ophthalmol. Vol. 128, pp. 1462-1471.

43. Schaumberg, D.A., Hankinson, S.E., Guo, Q., Rimm, E. et al. (2007), 'A prospective study of 2 major age-related macular degeneration susceptibility alleles and interactions with modifiable risk factors', Arch. Ophthalmol. Vol. 125, pp. 55-62.

44. Hollis, B.W., Kamerud, J.Q., Selvaag, S.R., Lorenz, J.D. et al. (1993), 'Determination of vitamin D status by radioimmunoassay with an 125I-labeled tracer', Clin. Chem. Vol. 39, pp. 529-533.

45. Chong, N.H.V., Keonin, J., Luthert, P.J., Frennesson, C.I. et al. (2005), 'Decreased thickness and integrity of the macular elastic layer of Bruch's membrane correspond to the distribution of lesions associated with age-related macular degeneration', Am. J. Pathol. Vol. 166, pp. $241-251$.

46. Hageman, G.S., Anderson, D.H., Johnson, L.V., Hancox, L.S. et al. (2005), 'A common haplotype in the complement regulatory gene factor $\mathrm{H}(\mathrm{HF} 1 / \mathrm{CFH})$ predisposes individuals to age-related macular degeneration'. Proc. Natl. Acad. Sci. USA Vol. 102, pp. 7227-7232.

47. Mullins, R.F., Russell, S.R., Anderson, D.H. and Hageman, G.S. (2000), 'Drusen associated with aging and age-related macular degeneration contain proteins common to extracellular deposits associated with atherosclerosis, elastosis, amyloidosis, and dense deposit disease', FASEB J. Vol. 14, pp. 835-846.

48. Seddon, J.M., Santangelo, S.L., Book, K., Chong, S. et al. (2003), 'A genomewide scan for age-related macular degeneration provides evidence for linkage to several chromosomal regions'. Am. J. Hum. Genet. Vol. 73, pp. 780-790.

49. Srivatsan, A., Han, Y., Peng, J., Tehranchi, A.K. et al. (2008), 'High-precision, whole-genome sequencing of laboratory strains facilitates genetic studies', PLoS Genet. Vol. 4, p. e1000139.

50. Andreoli, M.T., Morrison, M.A., Kim, B.J., Chen, L. et al. (2009), 'Comprehensive analysis of complement factor $\mathrm{H}$ and LOC387715/ ARMS2/HTRA1 variants with respect to phenotype in advanced age-related macular degeneration', Am. J. Ophthalmol. Vol. 148, pp. 869-874

51. DeAngelis, M.M., Ji, F., Kim, I.K., Adams, S. et al. (2007), 'Cigarette smoking, CFH, APOE, ELOVL4, and risk of neovascular age-related macular degeneration', Arch. Ophthalmol. Vol. 125, pp. 49-54.

52. Zhang, H., Morrison, M.A., Dewan, A., Adams, S. et al. (2008), 'The NEI/NCBI dbGAP database: Genotypes and haplotypes that may specifically predispose to risk of neovascular age-related macular degeneration', BMC Med. Genet. Vol. 9, p. 51.

53. Dudbridge, F. (2008), 'Likelihood-based association analysis for nuclear families and unrelated subjects with missing genotype data', Hum. Hered. Vol. 66, pp. 87-98.

54. Gabriel, S.B., Schaffner, S.F., Nguven, H., Moore, J.M. et al. (2002), 'The structure of haplotype blocks in the human genome', Science Vol. 296, pp. 2225-2229.

55. Francis, P.J., Schultz, D.W., Hamon, S., Ott, J. et al. (2007), 'Haplotypes in the complement factor $\mathrm{H}(\mathrm{CFH})$ gene: Associations with drusen and advanced age-related macular degeneration', PLoS ONE Vol. 2, p. e1197.

56. Dixon, A.L., Liang, L., Moffatt, M.F., Chen, W. et al. (2007), 'A genome-wide association study of global gene expression'. Nat. Genet. Vol. 39, pp. 1202-1207.

57. Moffatt, M.F., Kabesch, M., Liang, L., Dixon, A.L. et al. (2007), 'Genetic variants regulating ORMDL3 expression contribute to the risk of childhood asthma'. Nature Vol. 448, pp. 470-473.

58. Albert, D.M., Marcus, D.M., Gallo, J.P. and O'Brien, J.M. (1992), 'The antineoplastic effect of vitamin D in transgenic mice with retinoblastoma', Invest. Ophthalmol. Vis. Sci. Vol. 33, pp. 2354-2364.

59. Clark, A.G. (2004), 'The role of haplotypes in candidate gene studies', Genet. Epidemiol. Vol. 27, pp. 321-333.

60. Rivera, A., Fisher, S.A., Fritsche, L.G., Keilhauer, C.N. et al. (2005), 'Hypothetical LOC387715 is a second major susceptibility gene for age-related macular degeneration, contributing independently of complement factor $\mathrm{H}$ to disease risk', Hum. Mol. Genet. Vol. 14, pp. 3227-3236.

61. Yang, Z., Camp, N.J., Sun, H., Tong, Z. et al. (2006), 'A variant of the HTRA1 gene increases susceptibility to age-related macular degeneration', Science Vol. 314, pp. 992-993. 
62. Dewan, A., Liu, M., Hartman, S., Zhang, S.S.-M. et al. (2006), 'HTRA1 promoter polymorphism in wet age-related macular degeneration', Science Vol. 314, pp. 989-992.

63. Cantorna, M.T. (2006), 'Vitamin D and its role in immunology: Multiple sclerosis, and inflammatory bowel disease', Prog. Biophys. Mol. Biol. Vol. 92, pp. 60-64

64. Fears, T.R., Bird, C.C., Guerry, D., Sagebiel, R.W. et al. (2002), 'Average midrange ultraviolet radiation flux and time outdoors predict melanoma risk', Cancer Res. Vol. 62, pp. 3992-3996.

65. Solomon, C.C., White, E., Kristal, A.R. and Vaughan, T. (2004), 'Melanoma and lifetime UV radiation', Cancer Causes Control Vol. 15, pp. 893-902.

66. de Gruijl, FR. (2002), 'p53 mutations as a marker of skin cancer risk: Comparison of UVA and UVB effects', Exp. Dermatol. Vol. 11 (Suppl. 1), pp. 37-39.

67. The Eye Disease Case-Control Study Group (1992), 'Risk factors for neovascular age-related macular degeneration', Arch. Ophthalmol. Vol. 110, pp. $1701-1708$.

68. Cruickshanks, K.J., Klein, R. and Klein, B.E. (1993), 'Sunlight and age-related macular degeneration. The Beaver Dam Eye Study', Arch. Ophthalmol. Vol. 111, pp. 514-518.

69. Cruickshanks, K.J., Klein, R., Klein, B.E. and Nondahl, D.M. (2001), ' Sunlight and the 5-year incidence of early age-related maculopathy: The Beaver Dam Eye Study', Arch. Ophthalmol. Vol. 119, pp. 246-250.

70. Darzins, P., Mitchell, P. and Heller, R.F. (1997), 'Sun exposure and age-related macular degeneration. An Australian case-control study', Ophthalmology, Vol. 104, pp. 770-776.

71. Delcourt, C., Carrière, I., Ponton-Sanchez, A., Fourrey, S. et al. (2001), 'Light exposure and the risk of age-related macular degeneration: The Pathologies Oculaires Liées à l'Age (POLA) study', Arch. Ophthalmol. Vol. 119, pp. 1463-1468

72. Dillon, J., Zheng, L., Merriam, J.C. and Gaillard, E.R. (2004), 'Transmission of light to the aging human retina: Possible implications for age related macular degeneration', Exp. Eye Res. Vol. 79, pp. 753-759.

73. Fletcher, A.E., Bentham, G.C., Agnew, M., Young, I.S. et al. (2008), 'Sunlight exposure, antioxidants, and age-related macular degeneration'. Arch. Ophthalmol. Vol. 126, pp. 1396-1403.

74. McCarty, C.A., Mukesh, B.N., Fu, C.L., Mitchell, P. et al. (2001), 'Risk factors for age-related maculopathy: The Visual Impairment Project', Arch. Ophthalmol. Vol. 119, pp. 1455-1462.

75. Rosenthal, F.S., Phoon, C., Bakalian, A.E. and Taylor, H.R. (1988), 'The ocular dose of ultraviolet radiation to outdoor workers', Invest. Ophthalmol. Vis. Sci. Vol. 29, pp. 649-656.

76. Taylor, H.R., Muñoz, B., West, S., Bressler, N.M. et al. (1990), 'Visible light and risk of age-related macular degeneration'. Trans. Am. Ophthalmol. Soc. Vol. 88, pp. 163-173; discussion 173-178.

77. Tomany, S.C., Cruickshanks, K.J., Klein, R., Klein, B.E.K. et al. (2004), 'Sunlight and the 10-year incidence of age-related maculopathy: The Beaver Dam Eye Study', Arch. Ophthalmol. Vol. 122, pp. 750-757.

78. West, S.K., Rosenthal, F.S., Bressler, N.M., Bressler, S.B. et al. (1989), 'Exposure to sunlight and other risk factors for age-related macular degeneration', Arch. Ophthalmol. Vol. 107, pp. 875-879.

79. West, S.K., Duncan, D.D., Muñoz, B., Rubin, G.S. et al. (1998), 'Sunlight exposure and risk of lens opacities in a population-based study: The Salisbury Eye Evaluation project', JAMAVol. 280, pp. 714-718.

80. Khan, J.C., Shahid, H., Thurlby, D.A., Bradley, M. et al. (2006), 'Age related macular degeneration and sun exposure, iris colour, and skin sensitivity to sunlight', Br. J. Ophthalmol. Vol. 90, pp. 29-32.

81. Winkler, B.S., Boulton, M.E., Gottsch, J.D. and Sternberg, P. (1999), 'Oxidative damage and age-related macular degeneration', Mol. Vis. Vol. 5, p. 32.
82. Roduit, R. and Schorderet, D.F. (2008), 'MAP kinase pathways in UV-induced apoptosis of retinal pigment epithelium ARPE19 cells', Apoptosis Vol. 13, pp. 343-353.

83. Patton, W.P., Chakravarthy, U., Davies, R.J. and Archer, D.B. (1999), 'Comet assay of UV-induced DNA damage in retinal pigment epithelial cells', Invest. Ophthalmol. Vis. Sci. Vol. 40, pp. 3268-3275.

84. Tratsk, K.S. and Thanos, S. (2003), 'UV irradiation causes multiple cellular changes in cultured human retinal pigment epithelium cells', Graefes Arch. Clin. Exp. Ophthalmol. Vol. 241, pp. 852-859.

85. Chan, C.-M., Huang, J.-H., Lin, H.-H., Chiang, H.-S. et al. (2008), 'Protective effects of (-)-epigallocatechin gallate on UVA-induced damage in ARPE19 cells', Mol. Vis. Vol. 14, pp. 2528-2534.

86. Tobi, S.E., Gilbert, M., Paul, N. and McMillan, T.J. (2002), 'The green tea polyphenol, epigallocatechin-3-gallate, protects against the oxidative cellular and genotoxic damage of UVA radiation', Int. J. Cancer Vol. 102, pp. 439-444.

87. Mantena, S.K., Meeran, S.M., Elmets, C.A. and Katiyar, S.K. (2005), 'Orally administered green tea polyphenols prevent ultraviolet radiation-induced skin cancer in mice through activation of cytotoxic $\mathrm{T}$ cells and inhibition of angiogenesis in tumors', J. Nutr. Vol. 135, pp. $2871-2877$.

88. Berwick, M., Armstrong, B.K., Ben-Porat, L., Fine, J. et al. (2005), 'Sun exposure and mortality from melanoma', J. Natl. Cancer Inst. Vol. 97, pp. 195-199.

89. Smedby, K.E., Hjalgrim, H., Melbye, M., Torrång, A. et al. (2005), 'Ultraviolet radiation exposure and risk of malignant lymphomas', J. Natl. Cancer Inst. Vol. 97, pp. 199-209.

90. Meunier, L., Raison-Peyron, N. and Meynadier, J. (1998), ['UV-induced immunosuppression and skin cancers'], Rev. Med. Interne Vol. 19 , pp. 247-254

91. Vojniković, B., Njirić, S., Coklo, M. and Spanjol, J. (2007), 'Ultraviolet sun radiation and incidence of age-related macular degeneration on Croatian Island', Rab. Coll Antropol. Vol. 31 (Suppl. 1), pp. 43-44.

92. Vojniković, B., Synek, S., Mićović, V., Telezar, M. et al. (2010), 'Epidemiological study of sun exposure and visual field damage in children in Primorsko-Goranska County - The risk factors of earlier development of macular degeneration', Coll. Antropol. Vol. 34 (Suppl. 2), pp. $57-59$

93. Hyman, L.G., Lilienfeld, A.M., Ferris, F.L. and Fine, S.L. (1983), 'Senile macular degeneration: A case-control study', Am. J. Epidemiol. Vol. 118, pp. 213-227.

94. Millen, A.E., Voland, R., Sondel, S.A., Parekh, N. et al. (2011), 'Vitamin D status and early age-related macular degeneration in postmenopausal women', Arch. Ophthalmol. Vol. 129, pp. 481-489.

95. Holick, M.F. (2007), 'Vitamin D deficiency', N. Engl. J. Med. Vol. 357, pp. $266-281$.

96. Plum, L.A. and DeLuca, H.F. (2010), "Vitamin D, disease and therapeutic opportunities', Nat. Rev. Drug Discov. Vol. 9, pp. 941-955.

97. Toner, C.D., Davis, C.D. and Milner, J.A. (2010), 'The vitamin D and cancer conundrum: Aiming at a moving target', J. Am. Diet. Assoc. Vol. 110, pp. $1492-1500$.

98. Krishnan, A.V., Trump, D.L., Johnson, C.S. and Feldman, D. (2010), 'The role of vitamin D in cancer prevention and treatment', Endocrinol. Metab. Clin. North Am. Vol. 39, pp. 401-418.

99. Elmadfa, I. and Meyer, A.L. (2008), 'Body composition, changing physiological functions and nutrient requirements of the elderly', Ann. Nutr. Metab. Vol. 52 (Suppl. 1), pp. 2-5.

100. Zadshir, A., Tareen, N., Pan, D., Norris, K. et al. (2005), 'The prevalence of hypovitaminosis D among US adults: Data from the NHANES III', Ethn. Dis. Vol. 15 (4 Suppl. 5), pp. S5-97-S5-101. 


\section{Supplementary Materials}

Table SI. Subject characteristics

\begin{tabular}{|c|c|c|c|c|}
\hline Population & Mean age & Range & Standard deviation & $\%$ Male \\
\hline \multicolumn{5}{|c|}{$\begin{array}{l}\text { Massachusetts Eye and Ear Infirmary Extremely Discordant Sibling Pair Discovery Cohort ( } n=270 \text { individuals from } \\
\text { I } 35 \text { families) }\end{array}$} \\
\hline Neovascular subjects $(n=135)$ & 71.7 & $49.0-85.5$ & 8.0 & $47 \%$ \\
\hline Control subjects $(n=135)$ & 76.0 & $50.3-93.9$ & 7.6 & $39 \%$ \\
\hline \multicolumn{5}{|c|}{ Massachusetts Eye and Ear Infirmary Cohort Extended Sibling Pair Cohort ( $n=657$ individuals from 284 families) } \\
\hline Population & Mean age & Range & Standard deviation & $\%$ Male \\
\hline Neovascular subjects $(n=353)$ & 73.9 & $49.0-94.0$ & 7.8 & $41 \%$ \\
\hline Dry subjects $(n=106)$ & 77.6 & $58.2-100.6$ & 7.2 & $35 \%$ \\
\hline Control subjects $(n=198)$ & 75.4 & $50.3-94.3$ & 8.3 & $44 \%$ \\
\hline \multicolumn{5}{|c|}{ Central Greece cohort ( $n=344$ individuals) } \\
\hline Population & Mean age & Range & Standard deviation & $\%$ Male \\
\hline Neovascular subjects $(n=139)$ & 76.23 & $49.0-94.0$ & 7.5 & $45 \%$ \\
\hline Dry subjects $(n=84)$ & 74.52 & $52.0-91.0$ & 7.8 & $44 \%$ \\
\hline Control subjects $(n=12 \mid)$ & 73.53 & $48.0-88.0$ & 7.3 & $51 \%$ \\
\hline \multicolumn{5}{|c|}{ Prospective-based cohort derived from the Nurses' Health Study/Health Professionals Study ( $n=1,527$ individuals) } \\
\hline Population & Mean age & Range & Standard deviation & $\%$ Male \\
\hline Neovascular subjects $(n=164)$ & 61.1 & $42.7-74.0$ & 6.0 & $46 \%$ \\
\hline Dry subjects $(n=293)$ & 59.5 & $41.3-74.0$ & 5.7 & $18 \%$ \\
\hline Control subjects $(n=1070)$ & 60.2 & $41.3-74.0$ & 5.9 & $36 \%$ \\
\hline
\end{tabular}


Table S2. Genomic location of SNPs ${ }^{\dagger}$

\begin{tabular}{|c|c|c|c|}
\hline Gene & SNP & Exon/intron ${ }^{\ddagger}$ & Position (bp) \\
\hline \multirow[t]{4}{*}{ CYP27AI } & rsI|6777II* & Intron I & chr2: $219,669,375$ \\
\hline & rs7566656* & Intron I & chr2: $219,664,519$ \\
\hline & rs7594289* & Intron I & chr2: $219,652,286$ \\
\hline & rs933994* & Intron I & chr2: $219,650,616$ \\
\hline \multirow[t]{2}{*}{ CYP27BI } & rs8I76345* & Exon 5 & chrI2: $58,158,558$ \\
\hline & rs4646536* & Intron 6 & chrI2: $58,157,988$ \\
\hline \multirow[t]{25}{*}{ VDR } & rs45I6035* & Promoter & chr I2: $48,299,826$ \\
\hline & rs7299460* & Intron I & chrl2: $48,296,268$ \\
\hline & rs10783219* & Intron I & chr I2: 48,295,488 \\
\hline & rs7136534* & Intron I & chrI2: $48,294,626$ \\
\hline & rs3890733* & Intron 2 & chr I2: 48,289,373 \\
\hline & rsII574026* & Intron 2 & chrl2: $48,288,246$ \\
\hline & rsII574027* & Intron 2 & chrl2: $48,287,373$ \\
\hline & rs4237855* & Intron 2 & chr I2: 48,287,203 \\
\hline & rs4328262* & Intron 2 & chrl2: $48,285,648$ \\
\hline & rsIII68287* & Intron 2 & chrl2: $48,285,4 \mid 4$ \\
\hline & rs4760648* & Intron 2 & chrl2: $48,280,665$ \\
\hline & rs2853564* & Intron 2 & chr I2: $48,278,487$ \\
\hline & rs2238136* & Intron 2 & chr|2: $48,277,7 \mid 3$ \\
\hline & rs $2254210 *$ & Intron 3 & chr|2: $48,273,7 \mid 4$ \\
\hline & rs2228570 \$,* & Exon 4 & chrl2: $48,272,895$ \\
\hline & rsl0875693* & Intron 4 & chr I 2: $48,269,650$ \\
\hline & rs2239186* & Intron 4 & chrI2: $48,269,410$ \\
\hline & rs3782905* & Intron 4 & chr I2: 48,266, 167 \\
\hline & rs3819545* & Intron 4 & chrl2: $48,265,006$ \\
\hline & rs2189480* & Intron 4 & chrl2: $48,263,828$ \\
\hline & rs I2721370* & Intron 4 & chrl2: $48,262,073$ \\
\hline & rs|27|799|* & Intron 4 & chr I2: $48,259,126$ \\
\hline & rs2239179* & Intron 5 & chrl2: $48,257,766$ \\
\hline & rs2283342* & Intron 5 & chrl2: $48,255,859$ \\
\hline & rs2107301* & Intron 5 & chr I2: $48,255,570$ \\
\hline
\end{tabular}


Table S2. Continued

\begin{tabular}{|c|c|c|c|}
\hline Gene & SNP & Exon/intron & Position (bp) \\
\hline & rs2239182* & Intron 5 & chrl2: $48,255,4$ II \\
\hline & rsII574077* & Intron 5 & chrl2: $48,252,927$ \\
\hline & rsIII68267* & Intron 5 & chrl2: $48,25 \mathrm{I}, 542$ \\
\hline & rs7975I28* & Intron 8 & chrl2: $48,245,828$ \\
\hline & rsI5444I0* & Intron 10 & chrl2: $48,239,835$ \\
\hline & rs7975232* & Intron 10 & chrl2: $48,238,837$ \\
\hline & rs731236* & Exon II & chrl2: $48,238,757$ \\
\hline & rs3847987* & Exon II & chrl2: $48,238,068$ \\
\hline \multirow[t]{23}{*}{ CYP24AI } & rs2248359* & Promoter & chr20: 527915।8 \\
\hline & rs6022999* & Intron 3 & chr20: 52788013 \\
\hline & rs2585428* & Intron 3 & chr20: 52786897 \\
\hline & rs2245I53* & Intron 3 & chr20: 52786406 \\
\hline & rs229624l & Exon 4 & chr20: 52786219 \\
\hline & rs4809960* & Intron 4 & chr20: 52786073 \\
\hline & rs4809959* & Intron 4 & chr20: 52785859 \\
\hline & rs2181874* & Intron 4 & chr20: 52784478 \\
\hline & rs3787557* & Intron 4 & chr20: 52783135 \\
\hline & rs3787555* & Intron 4 & chr20: 52782691 \\
\hline & rs3787554* & Intron 4 & chr20: 52782680 \\
\hline & rs4809958* & Intron 4 & chr20: 52782438 \\
\hline & rs2762939* & Intron 5 & chr20: $5278 \mid 25 \mathrm{I}$ \\
\hline & rs60688I6* & Exon 6 & chr20: 52781091 \\
\hline & rs6022993 & Intron 7 & chr20: 52779247 \\
\hline & rs609|828 & Intron 7 & chr20: 52779210 \\
\hline & rs6127II9 & Intron 7 & chr20: 52779082 \\
\hline & c. $990+189 \mathrm{G}>\mathrm{A}$ & Intron 7 & chr20: 52779066 \\
\hline & rs6127II8* & Intron 7 & chr20: 52779052 \\
\hline & c. $990+222 \_223$ ins 99 & Intron 7 & chr20: 52779033 \\
\hline & rs2209314* & Intron 7 & chr20: 5277896 I \\
\hline & rs2296239 & Exon 8 & chr20: 52775528 \\
\hline & rs2274I30 & Intron 9 & chr20: 52774601 \\
\hline
\end{tabular}


Table S2. Continued

\begin{tabular}{|c|c|c|c|}
\hline Gene & SNP & Exon/intron $\neq$ & Position (bp) \\
\hline & rs I570670 & Intron 9 & chr20: 52774579 \\
\hline & rs 1977297 & Intron 9 & chr20: 52774479 \\
\hline & rsI570669* & Intron 9 & chr20: 52774427 \\
\hline & rs927650* & Intron II & chr20: 5277274I \\
\hline & rs2762934* & $3^{\prime} U T R$ & chr20: 5277|26I \\
\hline & rs4809957 & $3^{\prime} U T R$ & chr20: 5277| I7I \\
\hline & rs6022987 & $3^{\prime} U T R$ & chr20: 52770596 \\
\hline & rsII907350 & $3^{\prime}$ UTR & chr 20: 52770439 \\
\hline & rs 10623012 & $3^{\prime} U T R$ & chr20: $52770055-52770054$ \\
\hline & rs48II494 & $3^{\prime} U T R$ & chr20: 52769984 \\
\hline & rs2762933 & $3^{\prime}$ UTR & chr20: 52769903 \\
\hline & rs6097807* & $3^{\prime} U T R$ & chr20: 52769455 \\
\hline & rs6068810* & $3^{\prime}$ UTR & chr20: 5276935I \\
\hline
\end{tabular}

Abbreviations: chr, chromosomes; UTR, untranslated region; SNP, single nucleotide polymorphism.

†SNP chromosomal location according to Ensembl.

"Exon/intron description based on largest transcript listed in Ensembl.

$\S_{\mathrm{rs} 2228570}$ was formerly rs 10735810 .

*SNPs investigated in the initial discovery cohort. 